\title{
Potent universal-coronavirus therapeutic activity mediated by direct respiratory administration of a Spike S2 domain-specific human neutralizing monoclonal antibody
}

Michael S. Piepenbrink ${ }^{1+}$, Jun-Gyu Park ${ }^{2+}$, Ashlesha Desphande ${ }^{3,}$ Andreas Loos $^{4}$, Chengjin $\mathrm{Ye}^{2}$, Madhubanti Basu', Sanghita Sarkar ${ }^{1}$, David Chauvin ${ }^{4}$, Jennifer Woo ${ }^{4}$, Philip Lovalenti ${ }^{4}$, Nathaniel B. Erdmann ${ }^{1}$, Paul A. Goepfert ${ }^{1}$, Vu L. Truong ${ }^{4}$, Richard A. Bowen $^{5}$, Mark R. Walter ${ }^{3^{*}}$, Luis Martinez-Sobrido ${ }^{2^{*}}$, and James J. Kobie ${ }^{1^{*}}$

${ }^{1}$ Department of Medicine, Division of Infectious Diseases, University of Alabama at Birmingham, Birmingham, AL, USA

${ }^{2}$ Texas Biomedical Research Institute, San Antonio, TX, USA

${ }^{3}$ Department of Microbiology, University of Alabama at Birmingham, Birmingham, AL, USA

${ }^{4}$ Aridis Pharmaceuticals Inc., Los Gatos, CA, USA

${ }^{5}$ Department of Biomedical Sciences, Colorado State University, Fort Collins, CO, USA

${ }^{+}:$These authors contributed equally

*: correspondence 


\section{Abstract}

Severe Acute Respiratory Syndrome Coronavirus-2 (SARS-CoV-2) marks the third novel $\beta$-coronavirus to cause significant human mortality in the last two decades. Although vaccines are available, too few have been administered worldwide to keep the virus in check and to prevent mutations leading to immune escape. To determine if antibodies could be identified with universal coronavirus activity, plasma from convalescent subjects was screened for IgG against a stabilized pre-fusion SARS-CoV2 spike $S 2$ domain, which is highly conserved between human $\beta$-coronavirus. From these subjects, several S2-specific human monoclonal antibodies (hmAbs) were developed that neutralized SARS-CoV-2 with recognition of all variants of concern (VoC) tested (Beta, Gamma, Delta, Epsilon, and Omicron). The hmAb 1249A8 emerged as the most potent and broad hmAb, able to recognize all human $\beta$-coronavirus and neutralize SARS-CoV and MERS-CoV. 1249A8 demonstrated significant prophylactic activity in K18 hACE2 mice infected with SARS-CoV-2 lineage A and lineage B Beta, and Omicron VoC. $1249 \mathrm{~A} 8$ delivered as a single $4 \mathrm{mg} / \mathrm{kg}$ intranasal (i.n.) dose to hamsters 12 hours following infection with SARS-CoV-2 Delta protected them from weight loss, with therapeutic activity further enhanced when combined with $1213 \mathrm{H} 7$, an S1-specific neutralizing hmAb. As little as $2 \mathrm{mg} / \mathrm{kg}$ of 1249A8 i.n. dose 12 hours following infection with SARS-CoV Urbani strain, protected hamsters from weight loss and significantly reduced upper and lower respiratory viral burden. These results indicate in vivo cooperativity between $\mathrm{S} 1$ and S2 specific neutralizing hmAbs and that potent universal coronavirus neutralizing mAbs with therapeutic potential can be induced in humans and can guide universal coronavirus vaccine development. 


\section{Introduction}

SARS-CoV-2 is the third known emergence of a coronavirus (CoV) with the ability to cause substantial human morbidity and mortality. The SARS-CoV-2 pandemic has resulted in over 5 million deaths worldwide in two years and painfully highlights the vulnerability of humanity to novel CoV. Despite the rapid development of vaccines exhibiting high levels of efficacy and low levels of side effects, global vaccine implementation has been slow. As a result, SARS-CoV-2 virus has infected many human hosts, allowing for the evolution of new variants that have the potential to evade the immune response elicited by previous infection or vaccination.

Although first generation SARS-CoV-2 vaccines have been highly effective at preventing severe disease, including from $\mathrm{VoC}$, the humoral immunity induced by vaccination and natural infection is overwhelmingly dependent on a neutralizing antibody response targeted to the Receptor Binding Domain (RBD) of the Spike (S) glycoprotein. The RBD, which mediates the initial attachment of SARS-CoV-2 to its primary receptor, angiotensin converting enzyme 2 (ACE2), and the S1 domain overall have undergone substantial antigenic diversity since the initial emergence of SARSCoV-2. Mutations within RBD and S1 dramatically negate the neutralizing activity of plasma antibodies (Abs) against SARS-CoV-2 VoC that are generated from vaccinated or infected individuals and enhance the transmissibility and pathogenicity of VoC (1-4). A good example of significant immune escape is the emergence of the Omicron VoC, with numerous mutations in the RBD that contribute to reduced neutralization by therapeutic human monoclonal antibodies (hmAbs) which are against RBD, and by vaccine and infection -induced plasma $\operatorname{Abs}(5,6)$.

The Spike is assembled as a homotrimer with $~ 24$ molecules located on the surface of each SARS-CoV-2 virion (7). While being synthesized, the S protein is initially cleaved by furin or furin-like proprotein convertase in the Golgi resulting in the $\mathrm{S} 1$ domain being non-covalently linked to the S2 domain (i.e. stalk) of the protein (8). Mature viruses are released from infected cells after virus containing vesicles fuse with the cell membrane. $\mathrm{CoV} S$ is a class I virus fusion protein (9), with the $S 1$ domain mediating attachment primarily through its $\mathrm{RBD}$, while the $\mathrm{S} 2$ domain mediates fusion to the host cell membrane and entry. The SARS-CoV-2 viral fusion mechanism is conserved across 
numerous pathogen proteins including HIV envelope, influenza hemagglutinin, Ebola GP, and RSV fusion protein (10). While CoV S1 domains exhibit substantial variation to allow recognition of different host receptors, CoV S2 domains are highly conserved overall (90\% between SARS-CoV and SARS-CoV-2), which is consistent with their conserved function. For membrane fusion to occur a highly dynamic transformation must occur, requiring precise interactions of various S2 subdomains(11), suggesting there is low tolerance for $\mathrm{S} 2$ variation without compromising viral fitness. Antibody responses to $\mathrm{S} 2$ are increased in some individuals following SARS-CoV-2 infection and plasma S2 Ab response are associated with survival after coronavirus disease 2019 (COVID-19) infection(12). However, the development of S2-specific Abs following SARS-CoV-2 natural infection or standard vaccination is limited compared to those specific for $S 1(13,14)$. While most $S 1$ Abs are neutralizing, only a small fraction of $S 2$ Abs are neutralizing(13).

Many SARS-CoV-2 neutralizing antibodies also target the $\mathrm{N}$-terminal domain (NTD). While neutralizing Abs to NTE have been identified, new SARS-CoV-2 variants such as Omicron, have gained several mutations in the NTD and RBD of the Spike protein that promote immune evasion. With the substantial number of people unvaccinated and immunocompromised, and emergence of new variants that can evade immune protection, a great need remains for new therapeutics that neutralize SARS-CoV-2, despite its continued evolution. Furthermore, there is a potential treatment advantage of combining Abs that inhibit both ACE2 binding and viral fusion.

Therapeutic mAbs are typically delivered systemically through intravenous infusion or intramuscular injection, which is highly inefficient and slow in achieving optimal concentrations in the respiratory tract for the treatment of respiratory infections(15), including SARS-CoV-2(16). We have previously demonstrated that direct respiratory delivery of a SARS-CoV-2 RBD-specific hmAb enables substantial dose-sparing therapeutic activity in hamsters and here evaluate this delivery mechanism for the treatment of SARS-CoV-2 and SARS-CoV with a S2-specific hmAb.

To more precisely identify the potential of the SARS-CoV-2 S2 specific B cell response, a panel of S2-specific hmAbs were isolated and their molecular features, reactivity profiles, and in vitro and in vivo antiviral activities were defined. Several of these hmAbs 
demonstrate broad CoV reactivity, neutralizing, and antibody-dependent phagocytosis activity. With the most potent and broad S2-specific hmAb, $1249 \mathrm{~A} 8$ exhibiting prophylactic and therapeutic activity against SARS-CoV-2 and SARS-CoV in multiple animal models, demonstrating the universal CoV therapeutic potential of $\mathrm{S} 2 \mathrm{hmAb}$ directly. The combination of 1249A8 with and S1-speciific hmAb $1213 \mathrm{H} 7$ was evaluated for possible synergistic effects and delivered to the respiratory tract for improved dose delivery efficiency. 


\section{Results}

Identification and isolation of S2-specific human B cells. To identify SARS-CoV-2 S2specific human $B$ cells, two complementary recombinant proteins were designed and produced; a pre-fusion state stabilized SARS-CoV-2 (S2-STBL) and a SARSCoV/SARS-CoV-2 full Spike chimera consisting of SARS-CoV S1 and SARS-CoV-2 S2 (SARS-CoV-1/2 S1S2) (Figure 1A). Initial testing of plasma from COVID-19 convalescent patients was performed to identify those with high avidity lgG binding titers against S2 (Figure 1B). Using fluorescent S2-STBL and S1S2 chimera tetramers, peripheral blood memory $B$ cells from several subjects were single-cell sorted by flow cytometry (Figure 1C) and recombinant fully human IgG1 mAbs (hmAbs) were generated. Seventeen hmAbs with reactivity to SARS-CoV-2 S2 protein resulted (Figure 1D). In general, most hmAbs bound commercial preparations of SARS-CoV-2 $\mathrm{S}$, as well as S2-STBL and SARS-CoV-1/2, as shown in the plasma profiling. Binding to S2-STBL and SARS-CoV-1/2 S1S2 was more discriminating, as also evident in the plasma profiling. The previously reported S2-specific hmAb CC40.8 (17) was included as a positive control. Off-target binding to SARS-CoV-2 S1 was not evident.

S2 hmAbs have in vitro SARS-CoV-2 neutralizing and antibody-dependent phagocytosis activity. The functional activity of S2 hmAbs against SARS-CoV-2 was tested. The hmAbs that showed the greatest binding to at least one S2 protein by ELISA were tested by live virus and pseudovirus-based neutralization assays. Several hmAbs did not show neutralization capacity, even at the highest concentration $(50 \mu \mathrm{g} / \mathrm{ml})$ (Figure 2A+B). Eight hmAbs demonstrated neutralization of SARS-CoV-2 D614G pseudovirus (PsV) and were tested further, of which four hmAbs (1249A8, 1242C6, 1250D2, and 1235C10) effectively neutralized both PsV and live virus including Beta and Delta VoC. 1249A8 emerged as having the broadest and most potent neutralizing activity, with comparable $\mathrm{NT}_{50}$ (neutralization titer at 50\% inhibition) to CV3-25, a previously described S2 neutralizing hmAb (18), with the notable exception of SARSCoV-2 Beta which was not neutralized by CV3-25. 
The Fc effector function of the $\mathrm{S} 2 \mathrm{hmAbs}$ was assessed by antibody dependent cellular phagocytosis (ADCP) of SARS-CoV-2 Wuhan-Hu-1 Spike coated beads (Figure 2C). 1242F4 and 1250E10 had the highest ADCP activity, similar to the previously described S2-specific hmAb S2P6 (19). Both $1246 \mathrm{C} 2$ and $1246 \mathrm{H} 7$ had activity that was only slightly higher than the isotype control indicating very little Fc effector function, and consistent with their limited binding and neutralizing activity. 1249A8 had 4.2 fold greater ADCP activity than the isotype control which was similar to the S2 hmAbs CC40.8 and CV3-25. The SARS-CoV-2 RBD specific mAb $1213 \mathrm{H} 7(16,20,21)$, had the greatest ( $\sim 8$ times greater than isotype) ADCP activity. Together these results suggest S2 hmAbs have the potential to eliminate SARS-CoV-2 through both neutralization and Fc-dependent effector functions. Four S2 protein fragments (S2 Frag1-Frag4) that cover different regions of the S2 amino acid sequence were produced to identify the binding epitope of 1249A8 (Figure 2D). S2 fragment binding assays localized the 1249A8 binding epitope to S2 residues 1131-1171 (S2-Frag4), which contains the conserved stem helix region (residues 1148-1158) of S2, previously reported to be recognized by mAbs CV3-25 (18), CC40.8 (17), and S2P6 (19).

Molecular characteristics of S2 hmAbs. The most potent neutralizing hmAb, 1249A8 was isolated from an IgG1 expressing $B$ cell and exhibited substantial somatic hypermutation including $16.7 \%$ amino acid mutation from germline in the heavy chain variable region, and $7.6 \%$ amino acid mutation from germline in the light chain variable region (Table 1). The 1249A8 hmAb is member of the same clonal lineage that includes 1242C6, 1250D2, 1242F4, 1249D4, and 1249B7. This shared lineage utilizes VH1-46 heavy chain gene and VK3-20 light chain gene, with all members isolated from IgG1 expressing $B$ cells and demonstrating substantial somatic hypermutation in the heavy (15.6-18.8\% AA) and light (10.4-13.5\% AA) from germline.

$1249 A 8$ hmAb protects from SARS-CoV2 infection. The K18 human ACE2 transgenic mouse model was utilized to determine the prophylactic activity of 1249A8 hmAb. Mice were treated with a single dose of 1249A8 intraperitoneally (IP), and 12 hours later challenged with both rSARS-CoV-2 WA-1/Venus and rSARS-CoV-2 Beta/mCherry 
reporter viruses(21). Mice were also treated alone or in combination with a modest dose of $1213 \mathrm{H} 7$ (5 mg/kg), a broad and potent SARS-CoV-2 RBD specific hmAb we have previously described $(16,20,21)$. All mice treated with the isotype control hmAb had declining body weight following infection that required euthanasia by D9 (Figure 3A+B). Mice treated with $10 \mathrm{mg} / \mathrm{kg} 1249 \mathrm{~A} 8$ showed a milder weight loss with $60 \%$ of the mice surviving. Mice treated with $40 \mathrm{mg} / \mathrm{kg}$ of $1249 \mathrm{~A} 8$ prior to infection, as well as those treated with $1213 \mathrm{H} 7$ or the combination of both did not have weight loss and all survived. Both $10 \mathrm{mg} / \mathrm{kg}$ and $40 \mathrm{mg} / \mathrm{kg}$ 1249A8 significantly $(\mathrm{p}<0.05)$ reduced nasal virus at day (D) 2, with $1249 \mathrm{~A} 8$ and $1213 \mathrm{H} 7$ combination treated mice not having detectable virus, with all 1249A8 treated mice having viral titer below the limit of detection at D4 (Figure 3C), with viral burden dominated by rSARS-CoV-2 Beta/mCherry, as previously described(21). Lungs of mice that were treated with the isotype control mAb showed intense fluorescent radiance for both rSARS-CoV-2 WA1/Venus and rSARS-CoV-2 Beta/mCherry in left and right hemispheres by D2 following infection and markedly increased at D4, and minimally visually evident in the 1249A8, 1213H7, and combination treated mice (Figure 3D). Lung viral titer was reduced in mice treated with either 1249A8 doses by $\sim 2 \log$ at D2, and to below detection limit at D4 compared to isotype control hmAb treated mice (Figure 3E). The reduction in viral burden by 1249A8 was for both rSARS-CoV2 WA-1/Venus and rSARS-CoV2 Beta/mCherry (Figure 3E, F, G) and was consistent with significant $(p<0.05)$ reduction in lung pathology (Figure 3H). These results indicate that 1249A8 alone and in combination with the RBD mAb $1213 \mathrm{H} 7$ can broadly limit SARS-CoV-2 upper and lower respiratory viral burden and lung pathology, including the original lineage $A$ and the lineage B Beta VoC.

S2 hmAbs have broad $\beta$-coronavirus in vitro activity. Given the high conservation of S2 across CoV, the S2 hmAbs were evaluated for their binding and neutralization breadth against diverse SARS-CoV-2 variants and CoV. Vero E6 cells were infected with SARSCoV-2, SARS-CoV-2 variants, SARS-CoV, and MERS-CoV and binding assessed by immunofluorescence assay (IFA). Six of the hmAbs showed binding to all SARS-CoV-2 isolates, however the hmAb $1242 \mathrm{G} 6$ and 1246C2 bound poorly to SARS-CoV-2 infected 
cells (Figure 4A), consistent with their weak neutralizing activity. 1242C6, 1242F4, 1249A8 and 1250D2 all bound to SARS-CoV and MERS-CoV infected cells. CV3-25 had limited binding to SARS-CoV infected cells and no binding to MERS-CoV infected cells.

The breadth of the S2 binding activity of 1249A8 was further evaluated by avidity ELISA in the presence of urea, confirming its binding to SARS-CoV and MERS-CoV Spike, and also demonstrating its binding to OC43 and HKU-1 seasonal $\beta-\mathrm{CoV}$ (Figure 4B). No binding to the seasonal $\alpha-\operatorname{CoV} 229 \mathrm{E}$ or NL63 Spike proteins was detected (not shown). 1249A8 uniquely had substantial broad binding to recombinant $S$ proteins from MERSCoV, OC43, and HKU1 compared to CV3-25 and CC40.8 which did not recognize MERS-CoV S, and S2P6 which had lower reactivity to HKU-1 S compared to 1249A8 (Figure 4B). Consistent with the ELISA data, SPR/BLI studies 1249A8 exhibits high affinity for SARS-CoV-2 $(K D=1.8 \mathrm{nM})$, SARS-CoV $(K D=3.2 \mathrm{nM})$ and MERS-CoV $(K D=0.58 \mathrm{nM})$ Spikes. 1249A8 had higher affinity to SARS-CoV-2 and MERS-CoV Spikes as compared to S2P6, as a result of a S2P6 having a faster off-rate $(k d)$ (Figure 4C). 1249A8 effectively neutralizes both live SARS-CoV $\left(\mathrm{NT}_{50}=570 \mathrm{ng} / \mathrm{ml}\right)$ and MERSCoV $\left(\mathrm{NT}_{50}=5,830 \mathrm{ng} / \mathrm{ml}\right.$ ) (Figure 4D). As expected based on binding activity, CV3-25 did not neutralize MERS-CoV. Additionally, 1249A8 has ADCP activity against MERSCoV Spike coated beads (Figure 4E). These results indicate that several SARS-CoV-2 S2 specific hmAbs have broad beta-CoV reactivity, with 1249A8 demonstrating universal $\beta-\mathrm{CoV}$ functional activity.

Co-operative $S 1$ and $S 2$ neutralizing $m A b$ in vitro and in vivo activity against SARSCoV-2 Omicron. The emergence of the SARS-CoV-2 Omicron VoC and its substantial evasion of neutralizing antibodies $(2,5,6)$ necessitated testing of 1249A8. 1249A8 retains high affinity (KD $=0.52 \mathrm{nM}$ ) for the SARS-CoV-2 Omicron Spike (Figure 5A) and neutralizing activity $\left(\mathrm{NT}_{50}=2407 \mathrm{ng} / \mathrm{ml}\right)$ against live SARS-CoV-2 Omicron virus (Figure 5B). We also observed potent SARS-CoV-2 Omicron neutralization of $1213 \mathrm{H} 7$ $\left(\mathrm{NT}_{50}=64 \mathrm{ng} / \mathrm{ml}\right)$. As clinical development of an S2 mAb would likely include a RBD specific mAb, and as these mAbs target distinct Spike domains (S1 and S2) and steps in the infection process (attachment and fusion) we sought to determine their 
combinatorial activity. In the presence of $50 \mathrm{ng} / \mathrm{ml} 1213 \mathrm{H} 7$, the $\mathrm{NT}_{50}$ of $1249 \mathrm{~A} 8$ against SARS-CoV-2 Omicron was reduced to $1338 \mathrm{ng} / \mathrm{ml}$, and complementarily, in the presence of $2000 \mathrm{ng} / \mathrm{ml}$ of $1249 \mathrm{~A} 8$ the $\mathrm{NT}_{50}$ of $1213 \mathrm{H} 7$ was reduced to $26 \mathrm{ng} / \mathrm{ml}$, with similar effect observed for SARS-CoV-2 WA-1 (not shown), suggesting co-operative activity of the S2 and RBD mAbs in neutralizing SARS-CoV-2. Treatment of K18 hACE2 mice with 1249A8 alone i.p. prior to challenge with $10^{5}$ plaque forming units (PFU) of SARS-CoV-2 Omicron significantly reduced upper and lower respiratory viral burden compared to isotype control treated mice (Figure $5 \mathbf{C}+\mathbf{D}$ ). Treatment with $1213 \mathrm{H} 7$ alone i.p. also significantly reduced upper and lower respiratory viral burden. The combination of $1249 \mathrm{~A} 8$ and $1213 \mathrm{H} 7$ significantly reduced viral burden, being more pronounced when the hmAbs were administered directly to the respiratory tract through intranasal (i.n.) delivery, with $50 \%$ of the mice not having detectable virus in the nasal turbinate at D2 and D4, and lungs at day 2. None of the mice treated i.n. with the 1249A8 and $1213 \mathrm{H} 7$ combination had detectable virus in the lungs at D4. This was consistent with the significant reduction in lung pathology in these mice (Figure 5E). These results indicate that direct respiratory administration of the RBD and S2 mAb cocktail of $1213 \mathrm{H} 7$ and 1249A8, respectively significantly reduce SARS-CoV-2 Omicron viral burden through a cooperative effect.

Direct respiratory administration of $1249 A 8$ has broad $\beta$-coronavirus therapeutic activity. Given the broad $\beta$-CoV activity of 1249A8 in vitro and its demonstrated prophylactic activity against SARS-CoV-2 WA-1, Beta, and Omicron in K18 hACE2 mice, we evaluated its therapeutic potential in hamsters when delivered directly to the respiratory tract. Hamsters were infected with SARS-CoV-2 Delta and $12 \mathrm{~h} \mathrm{p.i.} \mathrm{were} \mathrm{treated} \mathrm{with} \mathrm{a}$ single dose of hmAb delivered intranasally. Isotype control hmAb treated and untreated hamsters exhibited $\sim 15 \%$ body weight loss within 6 days post infection (d p.i.), with minimal weight loss in hamsters treated with the $1249 \mathrm{~A} 8$ or $1213 \mathrm{H} 7$ alone, or in combination (Figure 6A). Combined treatment with $8 \mathrm{mg} / \mathrm{kg}$ of $1249 \mathrm{~A} 8$ and $2 \mathrm{mg} / \mathrm{kg}$ $1213 \mathrm{H} 7$ significantly reduced upper respiratory viral burden by $\sim 3$ logs (Figure 6B) and lower respiratory viral burden by $\sim 6$ logs (Figure $6 \mathrm{C}+\mathbf{D}$ ) compared to control groups. 
To assess pan $\beta$-CoV therapeutic activity, hamsters were infected with SARS-CoV, Urbani strain, and $12 \mathrm{~h}$ p.i. treated similarly with a single dose of hmAb delivered intranasally. As expected, untreated hamsters and those treated isotype control hmAb lost 15 to $20 \%$ of body weight by 7 d p.i.. Hamsters treated with 2, 4 or $8 \mathrm{mg} / \mathrm{kg}$ of $1249 \mathrm{~A} 8 \mathrm{had}<5 \%$ weight loss, and those treated with $8 \mathrm{mg} / \mathrm{kg} 1249 \mathrm{~A} 8$ alone or in combination with $2 \mathrm{mg} / \mathrm{kg}$ of $1213 \mathrm{H} 7$ actually gained weight by $7 \mathrm{~d}$ p.i. (Figure 7A). A significant reduction in upper respiratory viral burden between D1-D3 as determined by oropharyngeal swabbing was evident in all hmAb treated groups (Figure 7B). At D3 significant reduction in lung viral titer was evident in hamsters treated with 1249A8 alone and in combination with $1213 \mathrm{H} 7$ (Figure 7DE). These results indicate the S2 hmAb $1249 A 8$ has broad $\beta$-CoV in vivo therapeutic activity. 


\section{Discussion}

SARS-CoV-2 marks the third time in the last two decades a $\beta$-CoV has caused significant mortality in humans. SARS-CoV was originally discovered in Guangdong Province of China in 2002 and spread to five continents but no new cases have been detected since 2004. In 2012 MERS-CoV emerged in the Arabian Peninsula and continues to circulate today. SARS-CoV-2 has caused the most infections and deaths worldwide, new variants pose the risk of evading the immune system even in vaccinated and previously infected individuals, and there remains the potential for other genetically distinct CoV to emerge as new pandemic strains in the future. For these reasons, finding new therapeutic and prophylactic drugs, and vaccine strategies that have universal activity against $\mathrm{CoV}$ is essential for protecting humanity.

In SARS-CoV-2 infection, the RBD is immunodominant, having several antigenic sites that account for $90 \%$ of the neutralizing activity of convalescent plasma (22). Unfortunately, $\beta$-CoV cross-reactive Spike S1/RBD neutralizing antibodies are rare and most S1/RBD mAbs have a very narrow specificity. The Spike protein S2 domain is more highly conserved across $\beta-\mathrm{CoV}$, and here we have identified several hmAbs from convalescent patients that are highly cross reactive for all variants of SARS-CoV-2 tested. Further, four of these hmAbs also showed cross reactivity to SARS-CoV and MERS-CoV, with 1249A8 hmAb also effectively neutralizing SARS-CoV and MERSCoV and mitigating SARS-CoV-2 and SARS-CoV infection in animals.

A few S2-specific hmAbs with broad activity have been reported in the literature, and we have included them as possible for comparison in our in vitro assessments of 1249A8. 1249A8 is distinct from CV3-25 in its ability to neutralize SARS-CoV-2 Beta VoC, more potent neutralization of SARS-CoV-2 WA-1 consistent with its more potent protection from weight loss and death in K18 hACE2 mice (23), increased binding to OC43 and HKU-1 S, and its ability to bind and neutralize MERS-CoV(24). 1249A8 is distinct from S2P6 in its higher affinity for SARS-CoV-2 $S$ and MERS-CoV S, increased binding to HKU-1 S2, and ability to significantly prevent viral burden from SARS-CoV-2 Beta VoC infection(19). 1249A8 is distinct from CC40.8 in its ability to bind MERS-CoV S(17). Together these findings suggest that 1249A8 is a uniquely broad and potent $\mathrm{S} 2 \mathrm{hmAb}$ that universally recognizes all human $\beta-\mathrm{CoV} .1213 \mathrm{H} 7$ demonstrated remarkable breadth 
for an RBD-specific hmAb in its ability to neutralize all SARS-CoV-2 variants tested including recent Omicron VoC, which evaded many of the hmAbs that were being used clinically for treating COVID-19(25). This suggests that $1213 \mathrm{H} 7$ is well suited for the S1 targeting component of an S1/S2 hmAb cocktail for the treatment and prevention of SARS-CoV-2.

Our results suggest that 1249A8 recognizes a yet undefined epitope within stemhelix/HR2 region of S2, and crystallography efforts to precise determine the epitope are ongoing. The ability of $1249 \mathrm{~A} 8$ to directly neutralize $\beta-\mathrm{CoV}$ infection in vitro suggests its binding directly inhibits the post-attachment fusion process, however it remains to be determined at which step(s) such as fusion peptide insertion or 6-helix bundle formation it acts to prevent successful membrane fusion. Finer resolution of the mechanisms of S2 Ab mediated direct inhibition of fusion, and resolution of $\mathrm{S} 2$ epitope dynamics in native conformations is needed to adequately identify key $\beta-\mathrm{CoV}$ vulnerabilities.

Although direct inhibition of the viral attachment or fusion is most desired for the antiviral activities of Abs, through Fc fragment engagement, antibodies which may not necessarily bind to neutralizing motifs on infected cells can contribute to overall viral clearance. Antibodies against the S2 portion of the $S$ protein tend to be of lower neutralizing potency than antibodies targeting either the NTD or RBD, so Fc effector function may be of greater importance overall to the $\mathrm{S} 2 \mathrm{Ab}$ response. Although we demonstrated that 1249A8 (as well as others) has ADCP activity against SARS-CoV-2 and MERS-CoV, we do not know to what extent effector function plays in viral clearance. To limit effector function, Ullah et al.(23) introduced the LALA mutation into CV3-25 and found an increase in viral replication, invasion of the brain and body weight loss, while the GASDALIE mutation, which increases Fc effector function, decreased viral dissemination, provided $100 \%$ protection, leading to transient body weight loss, decreased viral titers and inflammatory cytokines. Likewise, when S2P6 was expressed as a hamster IgG because human IgG activates Fc receptors poorly in the hamster infection model, Pinto et al.(19) found that the hybrid mAb reduced replicating viral titers to a greater degree than the human counterpart. This context suggests that the Fceffector function of 1249A8 may contribute to in vivo viral clearance and warrants definitive assessment. 
The substantial somatic hypermutation that is observed in 1249A8 including $16.7 \% \mathrm{VH}$ and $13.5 \%$ Vk amino acid mutation from germline is higher than would be expected after a primary viral infection. And given its cross-reactivity with seasonal CoV OC43 and HKU-1 suggests that 1249A8 arose from a pre-existing memory B cell that was present in this individual prior to SARS-CoV-2 infection, with this lineage likely originating as a naïve $\mathrm{B}$ cell responding to a seasonal $\beta$-CoV infection that was expanded further as a consequence of SARS-CoV-2 infection. Given the sequence conservation in S2 among $\beta-\mathrm{CoV}$, and in light of recent work by Pinto et al., demonstrating S2P6 likely arose from an OC43-specific naïve B cell(19), it remains to be determined if there are constraints in the development of de novo S2 memory B cells and $\mathrm{Ab}$ responses following SARS-CoV-2 primary infection or vaccination. Determining whether such constraints are a consequence of a lifetime of seasonal $\beta-\mathrm{CoV}$ imprinting or limited immunogenicity of de novo SARS-CoV-2 S2 epitopes will be a fundamental for developing universal S2-based CoV vaccines that robustly and reproducibly confer protection in humanities landscape of variable CoV pre-existing immunity.

CoV utilize a variety of host receptors to gain entry, infect, and disseminate. The seasonal CoV including $\beta$-CoV OC43 and HKU1 infect through S1 binding to ubiquitous 9-O-acetyl sialic acid residues on host glycoproteins and lipids, $\alpha$-CoV 229E utilizes S1 binding to aminopeptidase N (CD13), and $\alpha-\mathrm{CoV}$ NL63 entry using both ACE2 and heparin sulfate proteoglycans; and $\beta$-CoV MERS-CoV uses dipeptidyl peptidase 4 (DPP4). Amongst the CoV, including $\beta$-CoV OC43 and HKU1, the precise binding sites for attachment receptors has still not been conclusively defined(26-28), suggesting possible heterogeneity or fluidity in the evolution of $\mathrm{CoV}$ as they adapt to humans. Although SARS-CoV-2 RBD binds with high affinity to ACE2, facilitating attachment to host cell and ultimate infection, and to date SARS-CoV-2 entry and pathology appears highly dependent on ACE2, some reports have described ACE2-independent SARSCoV-2 infection in vitro. This has included acquisition of the ability for heparin sulfate mediated infection of an ACE2-negative human lung epithelial as a result of the E484D mutation in the RBD(29), indeed in vitro evolution of SARS-CoV-2 to higher infectivity through more efficient binding to heparin sulfate has been reported(30), and in vivo reduction of intestinal ACE2 expression did not impact SARS-CoV-2 infection or 
severity(31), further suggesting the contribution of other cellular entry mechanisms. Several other receptors have been reported to facilitate ACE2-independent SARS-CoV2 infection, including the tyrosine-protein kinase receptor UFO (AXL)(32), LDLRAD3, and CLEC4G(33). While it is almost certain that the current SARS-CoV-2 VoC ravaging humanity are highly dependent on ACE2, as the high level of viral burden among the world's population continues, increasingly in people with pre-existing Abs to SARS-CoV2 through prior infection or vaccination, S2 hmAbs may provide protection against possible future variations in attachment receptor utilization by CoV.

Numerous SARS-CoV-2 RBD specific hmAbs have been approved for clinical use, and unfortunately several became irrelevant with their inability to neutralize $\mathrm{VoC}$, including Omicron, highlighting the perilous future of RBD only based mAb therapeutics against CoV. The ability of 1249 A 8 given as a single dose to mitigate SARS-CoV-2 pathology and viral burden against all VoC tested when used either prophylactically or therapeutically, along with the added benefit of combining with a broad and potent RBDspecific hmAb substantiate its clinical potential. Further we demonstrated that direct respiratory delivery of hmAb results in potent in vivo activity, consistent with our and others previous finding of its more rapid and efficient distribution of mAb to the airways compared to systemic administration(16, 34). The demonstrated activity of 1249A8 against all $\beta-\mathrm{CoV}$ further highlights its clinical potential against future SARS-CoV-2 VoCs, novel $\beta-C o V s$, as well as seasonal $\beta-C o V$. With recent advances in half-life extension of clinical mAbs, formulations as stabilized dry-powder, and easy inhaled delivery; a 1249A8 and 1213H7 hmAb or similar S2 and S1 hmAb cocktail could have substantial clinical potential for $\beta-\mathrm{CoV}$ prevention and treatment. Additionally, such a prophylactic cocktail may be beneficial for immunocompromised populations that do not mount strong durable responses to current COVID-19 vaccines. The increasing availability of oral SARS-CoV-2 antivirals such as nirmatrelvir/ritonavir (paxlovid) and molnupiravir are anticipated to significantly reduce SARS-CoV-2 hospitalizations and severe infections and ultimate health care burdens of the current pandemic. Their requirements for multiple doses, short half-life, and unknown potential for occurrence of resistant viruses may limit some aspects of their clinical utility. Further, a long-acting inhaled 1249A8 and $1213 \mathrm{H} 7$ cocktail may be advantageous manner of passive 
immunization for the substantial population that remains vaccine hesitant and those that are severely immunocompromised.

Overall, we describe a potent pan- $\beta$-CoV neutralizing S2 specific human mAb, 1249A8, and demonstrated its remarkable in vivo activity in multiple animal models against multiple SARS-CoV-2 VoC and SARS-CoV. We further demonstrate the clear clinical potential of 12498 including in combination with a potent SARS-CoV-2 RBD-specific $\mathrm{hmAb}, 1213 \mathrm{H} 7$, and value direct respiratory delivery. Its occurrence indicates that universal $\beta-\mathrm{CoV}$ neutralizing hmAbs that mitigate all $\beta$-CoVs including seasonal OC43 and HKU1 can be induced and suggests further studies of such mAbs can critically inform universal CoV vaccine development. 


\section{Materials and Methods}

Human subjects, sample collection, and B cell isolation. Peripheral blood was collected at the University of Alabama at Birmingham from adult convalescent patients approximately 1 month following PCR confirmed infection with SARS-CoV-2. The subjects provided informed consent. All procedures and methods were approved by the Institutional Review Board for Human Use at the University of Alabama at Birmingham, and all experiments were performed in accordance with relevant guidelines and regulations. Peripheral blood mononuclear cells (PBMC) were isolated by density gradient centrifugation and cryopreserved. S2-STBL and a SARS-CoV-1 / SARS-CoV-2 chimera (S1/S2) were used to generate tetramers for B-cell isolation. S2-STBL consists of the SARS-CoV-2 amino acid sequence (Wuhan-1) residues 696-1211, with mutations Q774C, L864C, S884C, A893C, K989-P, and V989P. The prefusion S1S2 chimera contains SARS-CoV-1 S residues 13-634 (uniprot P59594) and SARS-CoV-2 Wuhan-1 (P0DTC2) S residues 635-1211. The S1S2 sequence contains mutations R682S, R683-A, K989-P, and V989P. The C-termini of both proteins contain C-terminal T4 fibritin trimerization domains, his8 tags and biotinylation tags. The proteins were expressed in insect cells and purified by nickel affinity chromatography. The purified proteins were biotinylated using biotin ligase (BIRA, https://www.avidity.com/) and then used to form S2-STBL and S1S2 streptavidin tetramers for B cell isolation experiments. Cryopreserved cells were thawed and then stained for flow cytometry similar as previously described (16), using anti- CD19-APC-Cy7 (SJ25C1, BD Biosciences), HIV gp140-AlexaFluor488, S2-STBL-BV421, S1/S2 chimera-AlexaFluor647, CD3-BV510 (OKT3, Biolegend), CD4-BV510 (HI30, Biolegend), CD14-BV510 (63D3, Biolegend), CD27-PE (CLB-27/1,Life Technologies), Annexin V-PerCP-Cy5.5 (Biolegend), SABV421 (Biolegend), SA-AlexaFluor647 (Biolegend), and Live/Dead aqua (Molecular Probes).

Biosafety. All in vitro and in vivo experiments with live SARS-CoV-2, SARS-CoV, and MERS-CoV were conducted in appropriate biosafety level (BSL) 3 and animal BSL3 (ABSL3) laboratories at Texas Biomedical Research Institute and Colorado State University. Experiments were approved by the Texas Biomedical Research Institute 
and Colorado State University Biosafety and Animal Care and Use (IACUC) committees.

Monoclonal antibody production. Single B cells were sorted using a FACSMelody (BD Biosciences) into 96-well PCR plates containing $4 \mu \mathrm{l}$ of lysis buffer as previously described (35). Plates were immediately frozen at $-80^{\circ} \mathrm{C}$ after sorting until thawed for reverse transcription and nested PCR performed for $\lg \mathrm{H}$, $\lg \lambda$, and $\lg$ k variable gene transcripts as previously described $(35,36)$. Paired heavy and light chain genes were cloned into IgG1 expression vectors and were transfected into HEK293T cells and culture supernatant was concentrated using 100,000 MWCO Amicon Ultra centrifugal filters (Millipore-Sigma, Cork, Ireland), and IgG captured and eluted from Magne Protein A beads (Promega, Madison, WI) as previously described $(35,36)$. Immunoglobulin sequences were analyzed by IgBlast (www.ncbi.nlm.nih.gov/igblast) and IMGT/VQUEST (http://www.imgt.org/IMGT_vquest/vquest) to determine which sequences should lead to productive immunoglobulin, to identify the germline $V(D) J$ gene segments with the highest identity, and to scrutinize sequence properties. CV3-25, S2P6, and CC40.8 were previously described (17-19) and heavy and light chain variable regions synthesized by IDT based on reported sequences (GenBank: MW681575.1, GenBank: MW681603.1 and (19)) and cloned into IgG1 expression vector for production in HEK293T cell. 1249A8 hmAb used for in vivo experiments was modified to increase half-life with M252Y/S254T/T256E (YTE) mutations(37).

Cells and Viruses. African green monkey kidney epithelial cells (Vero E6, CRL-1586) were obtained from the American Type Culture Collection. A Vero E6 cell line expressing human ACE2 and TMPRSS2 (Vero AT) was obtained from BEI Resources (NR-54970). Cells were maintained in Dulbecco's modified Eagle medium (DMEM) supplemented with 5\% ( $\mathrm{vol} / \mathrm{vol})$ fetal bovine serum (FBS, VWR) and $1 \%$ penicillin-streptomycin-glutamine (PSG) solution (Corning). SARS-CoV-2 WA-1 (NR52281), SARS-CoV-2 Beta (NR-54008), SARS-CoV-2 Gamma (NR-54982), SARSCoV-2 Delta (NR-55611), and SARS-CoV-2 Omicron (NR-56461); SARS-CoV, Urbani strain icSARS-CoV (NR-18925); and MERS-CoV, icMERS-CoV-RFP- $\triangle O R F 5$ (NR- 
48813) were obtained from BEI Resources. SARS-CoV-2 Epsilon was kindly provided by Dr. Charles Chiu, UCSF. The recombinant reporter-expressing SARS-CoV-2 were generated previously $(21,38)$.

Binding characterization. ELISA plates (Nunc MaxiSorp; Thermo Fisher Scientific, Grand Island, NY) were coated with recombinant CoV proteins at $1 \square \mu \mathrm{g} / \mathrm{ml}$. Recombinant proteins used include SARS-CoV-2 S2, SARS-CoV-2 S1, SARS-CoV-2 S1+S2, MERS-CoV S2, OC43 S2, HKU1 S2 (Sino Biological, Wayne, PA), and SARSCoV S (BEI Resources). Human plasma or purified hmAbs were diluted in PBS, and binding was detected with HRP-conjugated anti-human IgG (Jackson ImmunoResearch, West Grove, PA). In select ELISAs, 8M urea were added to the ELISA plate and the plates incubated for $15 \square \mathrm{min}$ at room temperature prior to washing with PBS plus $0.05 \%$ Tween20 and detection with anti-lgG-HRP to evaluate avidity. Immunofluorescence assay was used to determine hmAb binding to SARSCoV-2, SARS-CoV, or MERS-CoV infected cells. Briefly, confluent monolayers of Vero E6 cells were mock infected or infected with the indicated virus. At $24 \square$ hours post infection (hpi), cells were fixed with $4 \%$ paraformaldehyde (PFA) for 30 minutes and permeabilized with $0.5 \%$ Triton X-100-PBS for $15 \mathrm{~min}$ at room temperature, and blocked with $2.5 \%$ Bovine Serum Albumin at $37^{\circ} \mathrm{C}$ for $1 \mathrm{~h}$. Cells were then incubated for $1 \square \mathrm{h}$ at $37^{\circ} \mathrm{C}$ with $1 \square \mu \mathrm{g} / \mathrm{ml}$ of indicated $\mathrm{hmAb}$. Then, cells were incubated with fluorescein isothiocyanate (FITC)-conjugated secondary anti-human Ab (Dako) for $1 \square \mathrm{h}$ at $37^{\circ} \mathrm{C}$. Images were captured using a fluorescence microscope and camera with a 10X objective. 
Bio-layer interferometry $(B L I)$. Experiments for $B L I$ were performed on a Gator Prime instrument at $30^{\circ} \mathrm{C}$ with shaking at $400-1000 \mathrm{rpm}$. All loading steps were $300 \mathrm{~s}$, followed by a 60 s baseline in KB buffer (1X PBS, $0.002 \%$ Tween 20, and $0.02 \% \mathrm{BSA}, \mathrm{pH} 7.4$ ), and then a 300 s association phase and a 300 s dissociation phase in $\mathrm{K}$ buffer. For the binding BLI experiments, mAbs were loaded at a concentration of $0.5 \mu \mathrm{g} / \mathrm{mL}$ in PBS onto Anti-Human IgG Fc capture (HFc) biosensors for a shift of $0.3 \mathrm{~nm}$. After baseline, probes were dipped into five two-fold serial dilutions of Spike protein from SARS-CoV-2, SARS-CoV, or MERS (all from Acro Biosystems, Newark, DE) starting at $50 \mathrm{nM}$ and a 0 $\mathrm{nM}$ for the association phase.

Surface Plasmon Resonance (SPR). SPR experiments were performed on a Biacore T200 (Cytiva) at $25^{\circ} \mathrm{C}$ using a running buffer consisting of $10 \mathrm{mM}$ HEPES, $150 \mathrm{mM} \mathrm{NaCl}$, $0.0075 \%$ P20. Binding comparisons between 1249A8, CC40.8, S2P6, and CV3-25 were performed by capturing the hmAbs to the chip surface of $\mathrm{CM}-5$ chips using a human antibody capture kit (cytiva). The binding kinetics for the interaction between hmAbs and SARS-CoV-2 Spike protein (R\&D Systems) was determined by injecting four concentrations of SARS-CoV-2 Spike ( $25 \mathrm{nM}$ highest concentration) with a contact time of 240 seconds and a 300 second dissociation phase. The same parameters were used to characterize MERS-CoV (Sino Biologicals) binding to the hmAbs. All SPR experiments were double referenced (e.g., sensorgram data was subtracted from a control surface and from a buffer blank injection). The control surface for all experiments consisted of the capture antibody. Sensorgrams were globally fit to a 1:1 model, without a bulk index correction, using Biacore T-200 evaluation software version 1.0.

CoV neutralization. hmAbs were tested for neutralization of live SARS-CoV-2, SARSCoV, and MERS-CoV as previously described (39). Vero E6 cells (96-well plate format, $4 \times 10^{4}$ cells/well, quadruplicate) were infected with 100-200 PFU/well of SARS-CoV-2. SARS-CoV-2 Omicron neutralization was performed in Vero AT using 600 PFU/well. After $1 \mathrm{~h}$ of viral adsorption, the infection media was changed with the $100 \mu$ l of postinfection media containing $1 \%$ Avicel and 2-fold dilutions, starting at $25 \mu \mathrm{g} / \mathrm{ml}$ of $\mathrm{hmAb}$ (or 1:100 dilution for human serum control). At $24 \mathrm{~h}$ p.i., infected cells were fixed with $10 \%$ neutral formalin for $24 \mathrm{~h}$ and were immune-stained using the anti-NP monoclonal 
antibody 1C7C7 (39). Virus neutralization was evaluated and quantified using ELISPOT, and the percentage of infectivity calculated using sigmoidal dose response curves. The formula to calculate percent viral infection for each concentration is given as [(Average \# of plaques from each treated wells - average \# of plaques from "no virus" wells)/(average \# of plaques from "virus only" wells - average \# of plaques from "no virus" wells)] x 100. A non-linear regression curve fit analysis over the dilution curve can be performed using GraphPad Prism to calculate NT $_{50}$. Mock-infected cells and viruses in the absence of hmAb were used as internal controls. hmAbs were also tested using a SARS-CoV-2 Spike protein pseudotyped virus (PsV) expressing firefly luciferase. Virus neutralization was measured by the reduction of luciferase expression. VeroE6/TMPRSS2 cells were seeded at $2 \times 10^{4}$ cells/well in opaque plates (Greiner 655083). The next day, PsV corresponding to $1-10 \times 10^{6}$ luciferase units was mixed in Opti-MEM with dilutions of hmAbs and incubated at RT for $1 \mathrm{~h}$. Media was removed from the cells and $100 \mu \mathrm{l} /$ well of the $\mathrm{hmAb} / \mathrm{PsV}$ mix was added in triplicates. After $1 \mathrm{~h}$ incubation at $37 \mathrm{C}$ and $5 \% \mathrm{CO}_{2}$, another $100 \mu \mathrm{L}$ of Opti-MEM was added, and cells were incubated for 24 more hours. After this time, luciferase activity was measured using Passive Lysis Buffer (Promega E1941) and Luciferase substrate (Promega E151A) following the manufacturer's instructions. Neutralization was calculated as the percent reduction of luciferase readings as compared to no-antibody-controls.

Antibody-Dependent Cellular Phagocytosis (ADCP) assay. ADCP activity of the mAbs was measured as previously described $(36,40)$ with slight modifications. Briefly, SARSCoV-2 Wuhan-Hu-1 Spike protein (NR-53524 BEI Resources) or MERS-CoV Spike protein (Sino Biological) was biotinylated with the Biotin-XX Microscale Protein Labeling Kit (Life Technologies, NY, USA). $0.25 \mu \mathrm{g}$ of biotinylated Ag or $\sim 0.16 \mu \mathrm{g}$ of BSA (used as a baseline control in an equivalent number of $\mathrm{Ag}$ molecules / bead) was incubated overnight at $4^{\circ} \mathrm{C}$ with $1.8 \times 10^{6}$ Yellow-Green neutravidin-fluorescent beads (Life Technologies) per reaction in a $25 \mu \mathrm{L}$ of final volume. Antigen-coated beads were subsequently washed twice in PBS-BSA (0.1\%) and transferred to a $5 \mathrm{~mL}$ Falcon round bottom tube (Thermo Fisher Scientific, NY, USA). mAbs, diluted at $5 \mu \mathrm{g} / \mathrm{ml}$, were added to each tube in a $20 \mu \mathrm{L}$ of reaction volume and incubated for a $2 \mathrm{~h}$ at $37^{\circ} \mathrm{C}$ in order to 
allow Ag-Ab binding. Then 250,000 THP-1 cells (human monocytic cell line obtained from NIH AIDS Reagent Program) were added to the cells and incubated for $3 \mathrm{~h}$ at $37^{\circ} \mathrm{C}$. At the end of incubation, $100 \mu \mathrm{L} 4 \%$ paraformaldehyde was added to fix the samples. Cells were then assayed for fluorescent bead uptake by flow cytometry using a BD Biosciences Symphony. The phagocytic score of each sample was calculated by multiplying the percentage of bead positive cells (frequency) by the degree of phagocytosis measured as mean fluorescence intensity (MFI) and dividing by $10^{6}$. Values were normalized to background values (cells and beads without mAb) and an isotype control to ensure consistency in values obtained on different assays. Finally, the phagocytic score of the testing mAb was expressed as the fold increase over BSAcoated beads.

K18 hACE2 transgenic mice experiments. All animal protocols involving K18 hACE2 transgenic mice were approved by the Texas Biomedical Research Institute IACUC (1718MU). Five-week-old female K18 hACE2 transgenic mice were purchased from The Jackson Laboratory and maintained in the animal facility at Texas Biomedical Research Institute under specific pathogen-free conditions and ABSL3 containment. For virus infection, mice were anesthetized following gaseous sedation in an isoflurane chamber and inoculated with viral dose of $10^{5}$ PFU per mouse, intranasally. For ex vivo imaging of lungs, mice were humanely euthanized at 2 and $4 \mathrm{~d}$ p.i. to collect lungs. Fluorescent images of lungs were photographed using an IVIS (AMI HTX), and the brightfield images of lungs were taken using an iPhone 6s (Apple). Nasal turbinate and lungs from mock or infected animals were homogenized in $1 \mathrm{~mL}$ of PBS for $20 \mathrm{~s}$ at 7,000 rpm using a Precellys tissue homogenizer (Bertin Instruments). Tissue homogenates were centrifuged at $12,000 \times \mathrm{g}\left(4^{\circ} \mathrm{C}\right)$ for $5 \mathrm{~min}$, and supernatants were collected and titrated by plaque assay and immunostaining as previously described. For the body weight and survival studies, five-week-old female K18 hACE2 transgenic mice were infected intranasally with $10^{5}$ PFU per animal following gaseous sedation in an isoflurane chamber. After infection, mice were monitored daily for morbidity (body weight) and mortality (survival rate) for $11 \mathrm{~d}$. Mice showing a loss of more than $25 \%$ of 
their initial body weight were defined as reaching the experimental end point and humanely euthanized.

Golden Syrian hamster experiments. Experiments using Syrian hamsters were approved for use by the Colorado State University IACUC. For each experiment, forty female Syrian hamsters (Envigo Corporation, Indianapolis, IN, USA) were housed in ventilated cages in separate rooms under ABSL3 containment. They were acclimated for 7-14 days after arrival and inoculated with virus at 6 weeks of age. Animals were challenged with virus under ketamine-xylazine anesthesia by intranasal instillation of $100 \mathrm{ul}$ of virus diluted in PBS to achieve a dose of $10^{4}$ CCID50 ((rSARS-CoV-2 Delta B.1.617.2 (hCoV-19/USA/CA-VRLC086/2021) BEI Resources (Manassas, VA, USA) or plaque-forming units (SARS-CoV, Urbani Strain; BEI Resources); the inocula were back-titrated after completion of the challenge to confirm dose delivered. Antibody therapies were administered as summarized in Figure 7 and 8 at 12 hours following virus inoculation, again under ketamine-xylazine anesthesia and by intranasal instillation of 100 ul. Oropharyngeal swabs were collected daily from all hamsters on days 1, 2 and 3 post-virus inoculation. Swabs were broken off into $1 \mathrm{ml}$ of BA1 medium (Tris-buffered minimal essential medium containing 1\% BSA) supplemented with $5 \%$ fetal bovine serum (BA1-FBS) and stored at -80C until assay. Half of the hamsters inoculated with virus were euthanized on day 3 and half on day 7 post-challenge. For the animals euthanized on day 3 , samples of nasal turbinates and cranial and caudal right lung were homogenized in BA1-FBS using a mixer mill and stainless-steel balls to obtain 10\% tissue homogenates. Infectious virus in tissue homogenates and oropharyngeal swabs was titrated by double-overlay plaque assay. Briefly, 10-fold serial dilutions of samples were prepared in BA1 medium with antibiotics, inoculated onto confluent monolayers of Vero cells in 6-well plates, incubated with rocking for 45 minutes, and then overlaid with 0.5\% agarose in phenol-red free MEM supplemented with antibiotics. Plates were incubated for one (SARS CoV) or two (SARS-CoV-2) days and second overlay containing neutral red dye was added. Plaques were counted 1 day after the second 
overlay. The limit of detection for this assay was $10 \mathrm{PFU} / \mathrm{swab}$ and $100 \mathrm{PFU} / \mathrm{gram}$ of tissue.

Statistical analysis. Significance was determined using GraphPad Prism, v8.0. Twotailed t-test were applied for evaluation of the results between treatments. $p<0.05$ was considered significant. For statistical analysis viral titers were log transformed and undetectable virus was set to the limit of detection. 


\section{Acknowledgments}

We are grateful for the clinical research staff that enabled this project and for the technical assistance provided by Christopher Bates, the technical guidance provided by Justin Roth, the virology expertise provided by llya Frolov, and the assistance of the University of Alabama at Birmingham (UAB) Center for AIDS Research and its Flow Cytometry Core Facility under the direction of Olaf Kutsch and the UAB Multidisciplinary Molecular Interaction Core Facility under the direction of Randall Davis. We thank Alexander Rosenberg and Christopher Fucile for providing immunoglobulin sequence analysis software. We thank Rachel Maison and Airn Hartwig for valuable assistance in conducting the hamster experiments. We are most grateful for the participation of the study volunteers. Funding for this work provided by institutional support from the University of Alabama at Birmingham (to J.J.K.) and the Texas Biomedical Research Institute (to L.M.-S.), funding from Aridis Pharmaceuticals, and the National Institutes of Health (1R01Al161175 to J.J.K., L-M.S, and M.R.W.) and funded Center for Research on Influenza Pathogenesis and Transmission (CRIPT), a NIAID-funded Center of Excellence for Influenza Research and Response (CEIRR, contract \# 75N93021C00014 to L.M-S.), and NIAID Preclinical and Clinical Services Contracts Division of Microbiology and Infectious Diseases, Respiratory Diseases Branch.

\section{Data Availability}

All relevant data are within the manuscript.

\section{Author contributions}

J.J.K., L.M.-S., M.R.W., R.A.B., and V.L.T. conceived the study. M.S.P., M.B., S.S., and J.J.K. isolated and screened the mAbs. M.S.P., J.J.K., M.R.W., and A.D. produced the mAbs. M.R.W. and A.D. designed and produced the recombinant S2 proteins and 
conducted the SPR analysis. M.B. conducted ADCP. J.-G.P., C.Y., R.A.B. and L.M.-S. conducted the in vitro and in vivo antiviral assessments. I.F. conducted in vitro antiviral assessments. R.A. B. conducted in vivo antiviral assessments. P.A.G. and N.B.E. acquired the clinical specimens. A.L. conducted the pseudovirus neutralization assay and BLI. J.W., P.L., and V.L.T. designed and conducted the experiments to determine the efficacy of mAbs. D.C., J.W., and P.L. provided expert advice. J.J.K., L.M.-S., M.R.W., R.A.B., and V.L.T. supervised the work. J.J.K., L.M.-S., M.R.W., R.A. B., and V.L.T. wrote the manuscript. All of the authors reviewed the manuscript.

\section{Declaration of interests}

M.S.P., J.-G.P., A.D., F.S.O., M.B., S.S., N.B.E., P.A.G., M.R.W., L.M.-S., and J.J.K. are co-inventors on patents that include claims related to the hmAbs described. A.L., D.C., J.W., P.L., and V.L.T. are employees of Aridis Pharmaceuticals. 


\section{Figure Legends}

Figure 1. Isolation of SARS-CoV-2 S2-specific human monoclonal antibodies (hmAbs) (A) Schematic representation of the S2-STBL and S1/S2 chimera proteins used as baits for ELISA and flow cytometry. (B) Human plasma from either convalescent or healthy subjects was diluted 1:1000 in PBS and used in an ELISA against indicated proteins; Absorbance at $450 \mathrm{nM}$ is shown. Each row is an individual subject. (C) Representative gating strategy for $\mathrm{S} 2+\mathrm{B}$ cell isolation. Initial plots are gated on live CD3-CD4-CD14-annexinV-CD19+CD27+ B cells. (D) hmAbs were tested at 10 and $1 \mu \mathrm{g} / \mathrm{ml}$ in duplicate by ELISA for binding to indicated protein; area under the curve $(A \cup C)$ is indicated.

Figure 2. in vitro neutralization and ADCP of SARS-CoV-2 by S2- specific hmAbs. (A) SARS-CoV-2 neutralization of S2 hmAbs. Vero E6 cells were infected with SARSCoV-2 WA-1 or SARS-CoV-2 Delta for $1 \mathrm{~h}$. After $1 \mathrm{~h}$ of viral adsorption, the indicated concentrations of S2 hmAbs were added and at 24 h.p.i., infected cells were fixed for virus titration by immunostaining assay. Data was expressed as mean and SD of quadruplicates. (B) Summary of viral neutralization (NT ${ }_{50}$ ) using either pseudovirus representing SARS-CoV-2 D614G mutation or Beta, or live SARS-CoV-2 WA-1 or Delta. (C) Ab-dependent cellular phagocytosis (ADCP) assay. SARS-CoV-2 Wuhan-Hu$1 \mathrm{~S}$-coated and BSA-coated beads were incubated with $5 \mu \mathrm{g} / \mathrm{ml} \mathrm{hmAb}$ for $2 \mathrm{~h}$ and then added to THP- 1 cells. After incubation for $3 \mathrm{~h}$ at $37^{\circ} \mathrm{C}$, cells were assayed for fluorescent bead uptake by flow cytometry. The ADCP score of each mAb was calculated by multiplying the percentage of bead positive cells (frequency of phagocytosis) by the mean fluorescence intensity (MFI) of the beads (degree of phagocytosis) and dividing by $10^{6}$. (D) Binding to S2 protein fragments by hmAbs (5 $\mu \mathrm{g} / \mathrm{ml}$ ) determined by ELISA.

Figure 3. Prophylactic activity of 1249A8 hmAb against rSARS-CoV-2 WA1-Venus and rSARS-CoV-2 Beta-mCherry in K18 ACE2 transgenic mice model. Female K18 hACE2 transgenic mice were treated i.p. with 1249A8 $(10 \mathrm{mg} / \mathrm{kg}$ or $40 \mathrm{mg} / \mathrm{kg}), 1213 \mathrm{H} 7$ ( $5 \mathrm{mg} / \mathrm{kg})$, alone or in combination, or isotype control hmAb $(40 \mathrm{mg} / \mathrm{kg})$, followed by infection with both rSARS-CoV-2 Venus and rSARS-CoV-2 Beta/mCherry Beta. Body weight $(\mathbf{A})$ and survival (B) were evaluated at the indicated days post-infection. Mice that loss $>25 \%$ of their body weight were humanely euthanized. Error bars represent standard deviations (SEM) of the mean for each group of mice. Viral titers in the nasal turbinate (C) and lung (E) at 2 and 4 DPI were determined by plaque assay in Vero E6 cells. Bars indicate the mean and SD of lung virus titers. Proportion of rSARS-CoV-2 WA-1/Venus and rSARS-CoV-2 Beta/mCherry determined by fluorescence (insets). (D) At 2 and $4 \mathrm{DPI}$, lungs were collected to determine Venus and mCherry fluorescence expression using an Ami HT imaging system. BF, bright field. (F) Venus (Green) and (G) mCherry (Red) radiance values were quantified based on the mean values for the 
regions of interest in mouse lungs. Mean values were normalized to the autofluorescence in mock-infected mice at each time point and were used to calculate fold induction. $(\mathbf{H})$ Gross pathological scores in the lungs of mock-infected and rSARSCoV-2-infected K18 hACE2 transgenic mice were calculated based on the percentage of area of the lungs affected by infection. Dotted line indicates limit of detection. * indicates $\mathrm{p}<0.05$ as compared to isotype control hmAb.

Figure 4. Universal $\beta$-coronavirus in vitro activity of $1249 \mathrm{~A} 8 \mathrm{hmAb}$. (A) Confluent monolayers of Vero E6 cells were infected (MOI 0.1) with SARS-CoV-2 WA-1, Beta (B.1.351), Gamma (P.1), or Epsilon (B.1.427/B.1.429). Mock-infected cells (bottom) were included as control. In a separate experiment, confluent monolayers of Vero E6 cells were infected (MOI 0.1) with SARS-CoV (Urbani v2163) or MERS-CoV (recombinant MERS-CoV-RFP delta ORF5 ic). Cells were incubated with the indicated primary $\mathrm{S} 2 \mathrm{hmAb}(1 \mu \mathrm{g} / \mathrm{ml})$ and developed with a FITC-conjugated secondary antihuman Ab. 4,6-Diamidino-2-phenylindole (DAPI; blue) was used for nuclear stain. As internal control, mock and SARS-CoV-2 WA-1 infected cells were stained with the mAb 3B4E10 or with a SARS-CoV cross-reactive NP mAb (1C7C7) or a ?-MERS NP pAb. Scale bars indicate $50 \mu \mathrm{m}$. (B) Binding of hmAb 1249A8 and other known S2-specific $\mathrm{mAb}$ to the Spike proteins of $\beta$-coronaviruses as determined by ELISA in the presence or absence of $8 \mathrm{M}$ urea. (C) Summary table of Surface Plasmon Resonance (SPR) and Biolayer Interferometry (BLI) of 1249A8 against the Spike protein of SARS-CoV-2, MERS-CoV, and SARS-CoV. (D) Viral neutralization by 1249A8 and CV3-25. Vero E6 cells were infected with 100 PFU of SARS-CoV (Urbani v2163) or MERS-CoV (recombinant MERS-CoV-RFP delta ORF5 ic) for $1 \mathrm{~h}$. After $1 \mathrm{~h}$ of viral adsorption, the indicated concentrations of S2 hmAbs were added. At 24 h.p.i., infected cells were fixed for virus titration by immunostaining assay. (E) ADCP of S2-specific mAb against MERS-CoV Spike coated beads.

Figure 5. Neutralization and prophylactic in vivo activity of $1249 \mathrm{~A} 8$ and $1213 \mathrm{H} 7$ against SARS-CoV-2 Omicron. (A) Binding of 1249A8 (60,40, 27, 18, $12 \mathrm{nM})$ to SARS-CoV-2 Wuhan and Omicron Spike protein determined by BLI. (B) Vero AT cells were infected with 600 pfu SARS-CoV-2 Omicron (BEIR) and after $1 \mathrm{~h}$ of viral adsorption, the indicated $\mathrm{mAb}(\mathrm{s})$ was added and at 24 h.p.i infected cells were fixed for virus titration by immunostaining assay. $1213 \mathrm{H} 7$ and 1249A8 were tested alone (open symbols) and together keeping $1213 \mathrm{H} 7$ constant $(50 \mathrm{ng} / \mathrm{ml})$ or $1249 \mathrm{~A} 8$ constant $(2$ $\mu \mathrm{g} / \mathrm{ml}$ ) and titrating the reciprocal mAb (closed symbols). Resulting $\mathrm{NT}_{50}(\mathrm{ng} / \mathrm{ml}$ ) are indicated. K18 hACE2 mice were treated with 1249A8 (40 mg/kg), 1213H7 (10 mg/kg), or isotype control mAb $(40 \mathrm{mg} / \mathrm{kg})$ either alone or in combination i.p. or i.n. as indicated and $24 \mathrm{~h}$ later challenged i.n. with $10^{5}$ PFU SARS-CoV-2 Omicron (BEIR) and virus titer in nasal turbinates (C) and lungs (D) determined at 2 and 4 dpi by plaque assay and gross lung pathology measured (E). Each symbol represents and individual animal. 
Dotted line indicates limit of detection. ${ }^{*}$ indicates $p<0.05$ compared to isotype control group as determined by $t$ test.

Figure 6. Therapeutic activity of intranasal 1249A8 and $1213 \mathrm{H} 7$ in hamsters infected with SARS-CoV-2 Delta. Golden Syrian hamsters were infected i.n. with $10^{4}$ $\mathrm{CCID}_{50}$ SARS-CoV-2 Delta and $12 \mathrm{~h}$ p.i. treated i.n. with a single dose of indicated $\mathrm{mAb}(\mathrm{s})$. $\mathrm{n}=4-8$ per group. (A) Body weight was measured daily. Mean $\pm \mathrm{SEM}$ indicated. Nasal turbinate (B), cranial lung (C), and caudal lung (D) viral titers were measured at 3 d p.i. by plaque assay. Each symbol represents an individual animal. Dotted line indicates limit of detection. *indicates $p<0.05$ compared to isotype control group as determined by $t$ test.

Figure 7. Therapeutic activity of intranasal $1249 \mathrm{~A} 8$ and $1213 \mathrm{H} 7$ in hamsters infected with SARS-CoV. Golden Syrian hamsters were infected i.n. with $10^{4}$ pfu SARS-CoV (SARS-Urbani) and $12 \mathrm{~h}$ p.i. treated i.n. with a single dose of indicated $\mathrm{mAb}(\mathrm{s})$. $\mathrm{n}=4-8$ per group. (A) Body weight was measured daily. Mean $\pm \mathrm{SEM}$ indicated. (B) Oropharyngeal swabs were collected days 1, 2, and 3 p.i. and sum of virus titer indicated. Nasal turbinate (C), cranial lung (C), and caudal lung (E) viral titers were measured at $3 \mathrm{~d}$ p.i. by plaque assay. Each symbol represents an individual animal. *indicates $p<0.05$ compared to isotype control group as determined by t test. 


\section{References}

1. Focosi D, Maggi F, Franchini M, McConnell S, Casadevall A. 2021. Analysis of Immune Escape Variants from Antibody-Based Therapeutics against COVID-19: A Systematic Review. Int J Mol Sci 23.

2. Cele S, Jackson L, Khoury DS, Khan K, Moyo-Gwete T, Tegally H, San JE, Cromer D, Scheepers C, Amoako DG, Karim F, Bernstein M, Lustig G, Archary D, Smith M, Ganga Y, Jule Z, Reedoy K, Hwa SH, Giandhari J, Blackburn JM, Gosnell BI, Abdool Karim SS, Hanekom W, Ngs SA, Team C-K, von Gottberg A, Bhiman JN, Lessells RJ, Moosa MS, Davenport MP, de Oliveira T, Moore PL, Sigal A. 2021. Omicron extensively but incompletely escapes Pfizer BNT162b2 neutralization. Nature doi:10.1038/s41586-021-04387-1.

3. Papanikolaou V, Chrysovergis A, Ragos V, Tsiambas E, Katsinis S, Manoli A, Papouliakos S, Roukas D, Mastronikolis S, Peschos D, Batistatou A, Kyrodimos E, Mastronikolis N. 2022. From delta to Omicron: S1-RBD/S2 mutation/deletion equilibrium in SARS-CoV-2 defined variants. Gene 814:146134.

4. Thakur V, Bhola S, Thakur P, Patel SKS, Kulshrestha S, Ratho RK, Kumar P. 2021. Waves and variants of SARS-CoV-2: understanding the causes and effect of the COVID-19 catastrophe. Infection doi:10.1007/s15010-021-01734-2.

5. Shah M, Woo HG. 2021. Omicron: A Heavily Mutated SARS-CoV-2 Variant Exhibits Stronger Binding to ACE2 and Potently Escapes Approved COVID-19 Therapeutic Antibodies. Front Immunol 12:830527.

6. Wratil PR, Stern M, Priller A, Willmann A, Almanzar G, Vogel E, Feuerherd M, Cheng CC, Yazici S, Christa C, Jeske S, Lupoli G, Vogt T, Albanese M, MejiasPerez E, Bauernfried S, Graf N, Mijocevic H, Vu M, Tinnefeld K, Wettengel J, Hoffmann D, Muenchhoff M, Daechert C, Mairhofer H, Krebs S, Fingerle V, Graf A, Steininger $P$, Blum H, Hornung V, Liebl B, Uberla K, Prelog M, Knolle P, Keppler OT, Protzer U. 2022. Three exposures to the spike protein of SARSCoV-2 by either infection or vaccination elicit superior neutralizing immunity to all variants of concern. Nat Med doi:10.1038/s41591-022-01715-4.

7. Ke Z, Oton J, Qu K, Cortese M, Zila V, McKeane L, Nakane T, Zivanov J, Neufeldt CJ, Cerikan B, Lu JM, Peukes J, Xiong X, Krausslich HG, Scheres SHW, Bartenschlager R, Briggs JAG. 2020. Structures and distributions of SARS-CoV-2 spike proteins on intact virions. Nature 588:498-502.

8. Hoffmann M, Kleine-Weber H, Pohlmann S. 2020. A Multibasic Cleavage Site in the Spike Protein of SARS-CoV-2 Is Essential for Infection of Human Lung Cells. Mol Cell 78:779-784 e5.

9. Bosch BJ, van der Zee R, de Haan CA, Rottier PJ. 2003. The coronavirus spike protein is a class I virus fusion protein: structural and functional characterization of the fusion core complex. J Virol 77:8801-11.

10. White JM, Delos SE, Brecher M, Schornberg K. 2008. Structures and mechanisms of viral membrane fusion proteins: multiple variations on a common theme. Crit Rev Biochem Mol Biol 43:189-219.

11. Jackson CB, Farzan M, Chen B, Choe H. 2022. Mechanisms of SARS-CoV-2 entry into cells. Nat Rev Mol Cell Biol 23:3-20. 
12. Kaplonek P, Wang C, Bartsch Y, Fischinger S, Gorman MJ, Bowman K, Kang J, Dayal D, Martin P, Nowak RP, Villani AC, Hsieh CL, Charland NC, Gonye ALK, Gushterova I, Khanna HK, LaSalle TJ, Lavin-Parsons KM, Lilley BM, Lodenstein CL, Manakongtreecheep K, Margolin JD, McKaig BN, Rojas-Lopez M, Russo BC, Sharma N, Tantivit J, Thomas MF, Sade-Feldman M, Feldman J, Julg B, Nilles EJ, Musk ER, Menon AS, Fischer ES, McLellan JS, Schmidt A, Goldberg MB, Filbin MR, Hacohen N, Lauffenburger DA, Alter G. 2021. Early cross-coronavirus reactive signatures of humoral immunity against COVID-19. Sci Immunol 6:eabj2901.

13. Crowley AR, Natarajan H, Hederman AP, Bobak CA, Weiner JA, Wieland-Alter W, Lee J, Bloch EM, Tobian AAR, Redd AD, Blankson JN, Wolf D, Goetghebuer T, Marchant A, Connor RI, Wright PF, Ackerman ME. 2021. Boosting of CrossReactive Antibodies to Endemic Coronaviruses by SARS-CoV-2 Infection but not Vaccination with Stabilized Spike. medRxiv doi:10.1101/2021.10.27.21265574.

14. Pannus P, Neven KY, De Craeye S, Heyndrickx L, Vande Kerckhove S, Georges D, Michiels J, Francotte A, Van Den Bulcke M, Zrein M, Van Gucht S, Schmickler M-N, Verbrugghe M, Matagne A, Thomas I, Dierick K, Weiner JA, Ackerman ME, Goriely S, Goossens ME, Ariën KK, Desombere I, Marchant A. 2021. Poor antibody response to BioNTech/Pfizer COVID-19 vaccination in SARS-CoV-2 naïve residents of nursing homes. Clinical Infectious Diseases doi:10.1093/cid/ciab998.

15. Magyarics Z, Leslie F, Bartko J, Rouha H, Luperchio S, Schorgenhofer C, Schwameis M, Derhaschnig U, Lagler H, Stiebellehner L, Firbas C, Weber S, Campanaro E, Jilma B, Nagy E, Stevens C. 2019. Randomized, Double-Blind, Placebo-Controlled, Single-Ascending-Dose Study of the Penetration of a Monoclonal Antibody Combination (ASN100) Targeting Staphylococcus aureus Cytotoxins in the Lung Epithelial Lining Fluid of Healthy Volunteers. Antimicrob Agents Chemother 63.

16. Piepenbrink MS, Park JG, Oladunni FS, Deshpande A, Basu M, Sarkar S, Loos A, Woo J, Lovalenti P, Sloan D, Ye C, Chiem K, Bates CW, Burch RE, Erdmann NB, Goepfert PA, Truong VL, Walter MR, Martinez-Sobrido L, Kobie JJ. 2021. Therapeutic activity of an inhaled potent SARS-CoV-2 neutralizing human monoclonal antibody in hamsters. Cell Rep Med 2:100218.

17. Zhou P, Yuan M, Song G, Beutler N, Shaabani N, Huang D, He WT, Zhu X, Callaghan S, Yong P, Anzanello F, Peng L, Ricketts J, Parren M, Garcia E, Rawlings SA, Smith DM, Nemazee D, Teijaro JR, Rogers TF, Wilson IA, Burton DR, Andrabi R. 2021. A protective broadly cross-reactive human antibody defines a conserved site of vulnerability on beta-coronavirus spikes. bioRxiv doi:10.1101/2021.03.30.437769.

18. Jennewein MF, MacCamy AJ, Akins NR, Feng J, Homad LJ, Hurlburt NK, Seydoux E, Wan YH, Stuart AB, Edara VV, Floyd K, Vanderheiden A, Mascola JR, Doria-Rose N, Wang L, Yang ES, Chu HY, Torres JL, Ozorowski G, Ward $A B$, Whaley RE, Cohen KW, Pancera M, McElrath MJ, Englund JA, Finzi A, Suthar MS, McGuire AT, Stamatatos L. 2021. Isolation and characterization of cross-neutralizing coronavirus antibodies from COVID-19+ subjects. Cell Rep 36:109353. 
19. Pinto D, Sauer MM, Czudnochowski N, Low JS, Tortorici MA, Housley MP, Noack J, Walls AC, Bowen JE, Guarino B, Rosen LE, di lulio J, Jerak J, Kaiser $\mathrm{H}$, Islam S, Jaconi S, Sprugasci N, Culap K, Abdelnabi R, Foo C, Coelmont L, Bartha I, Bianchi S, Silacci-Fregni C, Bassi J, Marzi R, Vetti E, Cassotta A, Ceschi A, Ferrari P, Cippa PE, Giannini O, Ceruti S, Garzoni C, Riva A, Benigni F, Cameroni E, Piccoli L, Pizzuto MS, Smithey M, Hong D, Telenti A, Lempp FA, Neyts J, Havenar-Daughton C, Lanzavecchia A, Sallusto F, Snell G, Virgin HW, Beltramello M, et al. 2021. Broad betacoronavirus neutralization by a stem helixspecific human antibody. Science 373:1109-1116.

20. Deshpande A, Harris BD, Martinez-Sobrido L, Kobie JJ, Walter MR. 2021. Epitope Classification and RBD Binding Properties of Neutralizing Antibodies Against SARS-CoV-2 Variants of Concern. Front Immunol 12:691715.

21. Chiem K, Morales Vasquez D, Silvas JA, Park JG, Piepenbrink MS, Sourimant J, Lin MJ, Greninger AL, Plemper RK, Torrelles JB, Walter MR, de la Torre JC, Kobie JK, Ye C, Martinez-Sobrido L. 2021. A Bifluorescent-Based Assay for the Identification of Neutralizing Antibodies against SARS-CoV-2 Variants of Concern In Vitro and In Vivo. J Virol 95:e0112621.

22. Piccoli L, Park YJ, Tortorici MA, Czudnochowski N, Walls AC, Beltramello M, Silacci-Fregni C, Pinto D, Rosen LE, Bowen JE, Acton OJ, Jaconi S, Guarino B, Minola A, Zatta F, Sprugasci N, Bassi J, Peter A, De Marco A, Nix JC, Mele F, Jovic S, Rodriguez BF, Gupta SV, Jin F, Piumatti G, Lo Presti G, Pellanda AF, Biggiogero M, Tarkowski M, Pizzuto MS, Cameroni E, Havenar-Daughton C, Smithey M, Hong D, Lepori V, Albanese E, Ceschi A, Bernasconi E, Elzi L, Ferrari P, Garzoni C, Riva A, Snell G, Sallusto F, Fink K, Virgin HW, Lanzavecchia A, Corti D, Veesler D. 2020. Mapping Neutralizing and Immunodominant Sites on the SARS-CoV-2 Spike Receptor-Binding Domain by Structure-Guided High-Resolution Serology. Cell 183:1024-1042 e21.

23. Ullah I, Prevost J, Ladinsky MS, Stone H, Lu M, Anand SP, Beaudoin-Bussieres G, Symmes K, Benlarbi M, Ding S, Gasser R, Fink C, Chen Y, Tauzin A, Goyette G, Bourassa C, Medjahed H, Mack M, Chung K, Wilen CB, Dekaban GA, Dikeakos JD, Bruce EA, Kaufmann DE, Stamatatos L, McGuire AT, Richard J, Pazgier M, Bjorkman PJ, Mothes W, Finzi A, Kumar P, Uchil PD. 2021. Live imaging of SARS-CoV-2 infection in mice reveals that neutralizing antibodies require Fc function for optimal efficacy. Immunity 54:2143-2158 e15.

24. Hurlburt NK, Homad LJ, Sinha I, Jennewein MF, MacCamy AJ, Wan Y-H, Boonyaratanakornkit J, Sholukh AM, Zhou P, Burton DR, Andrabi R, Stamatatos L, Pancera M, McGuire AT. 2021. Structural definition of a pan-sarbecovirus neutralizing epitope on the spike S2 subunit. bioRxiv doi:10.1101/2021.08.02.454829:2021.08.02.454829.

25. Gruell H, Vanshylla K, Tober-Lau P, Hillus D, Schommers P, Lehmann C, Kurth F, Sander LE, Klein F. 2022. mRNA booster immunization elicits potent neutralizing serum activity against the SARS-CoV-2 Omicron variant. Nat Med doi:10.1038/s41591-021-01676-0.

26. Hulswit RJG, Lang Y, Bakkers MJG, Li W, Li Z, Schouten A, Ophorst B, van Kuppeveld FJM, Boons GJ, Bosch BJ, Huizinga EG, de Groot RJ. 2019. Human coronaviruses OC43 and HKU1 bind to 9-O-acetylated sialic acids via a 
conserved receptor-binding site in spike protein domain A. Proc Natl Acad Sci U S A 116:2681-2690.

27. Szczepanski A, Owczarek K, Bzowska M, Gula K, Drebot I, Ochman M, Maksym B, Rajfur Z, Mitchell JA, Pyrc K. 2019. Canine Respiratory Coronavirus, Bovine Coronavirus, and Human Coronavirus OC43: Receptors and Attachment Factors. Viruses 11.

28. Ou X, Guan H, Qin B, Mu Z, Wojdyla JA, Wang M, Dominguez SR, Qian Z, Cui S. 2017. Crystal structure of the receptor binding domain of the spike glycoprotein of human betacoronavirus HKU1. Nat Commun 8:15216.

29. Puray-Chavez M, LaPak KM, Schrank TP, Elliott JL, Bhatt DP, Agajanian MJ, Jasuja R, Lawson DQ, Davis K, Rothlauf PW, Jo H, Lee N, Tenneti K, Eschbach JE, Mugisha CS, Vuong HR, Bailey AL, Hayes DN, Whelan SPJ, Horani A, Brody SL, Goldfarb D, Major MB, Kutluay SB. 2021. Systematic analysis of SARS-CoV2 infection of an ACE2-negative human airway cell. bioRxiv doi:10.1101/2021.03.01.433431.

30. Shiliaev N, Lukash T, Palchevska O, Crossman DK, Green TJ, Crowley MR, Frolova El, Frolov I. 2021. Natural and Recombinant SARS-CoV-2 Isolates Rapidly Evolve In Vitro to Higher Infectivity through More Efficient Binding to Heparan Sulfate and Reduced S1/S2 Cleavage. J Virol 95:e0135721.

31. Hsieh CL, Werner AP, Leist SR, Stevens LJ, Falconer E, Goldsmith JA, Chou CW, Abiona OM, West A, Westendorf K, Muthuraman K, Fritch EJ, Dinnon KH, 3rd, Schafer A, Denison MR, Chappell JD, Baric RS, Graham BS, Corbett KS, McLellan JS. 2021. Stabilized coronavirus spike stem elicits a broadly protective antibody. Cell Rep 37:109929.

32. Wang S, Qiu Z, Hou Y, Deng X, Xu W, Zheng T, Wu P, Xie S, Bian W, Zhang C, Sun Z, Liu K, Shan C, Lin A, Jiang S, Xie Y, Zhou Q, Lu L, Huang J, Li X. 2021. $A X L$ is a candidate receptor for SARS-CoV-2 that promotes infection of pulmonary and bronchial epithelial cells. Cell Res 31:126-140.

33. Zhu S, Liu Y, Zhou Z, Zhang Z, Xiao X, Liu Z, Chen A, Dong X, Tian F, Chen S, Xu Y, Wang C, Li Q, Niu X, Pan Q, Du S, Xiao J, Wang J, Wei W. 2021. Genome-wide CRISPR activation screen identifies candidate receptors for SARS-CoV-2 entry. Sci China Life Sci doi:10.1007/s11427-021-1990-5.

34. Parray HA, Shukla S, Perween R, Khatri R, Shrivastava T, Singh V, Murugavelu P, Ahmed S, Samal S, Sharma C, Sinha S, Luthra K, Kumar R. 2021. Inhalation monoclonal antibody therapy: a new way to treat and manage respiratory infections. Appl Microbiol Biotechnol 105:6315-6332.

35. Nogales A, Piepenbrink MS, Wang J, Ortega S, Basu M, Fucile CF, Treanor JJ, Rosenberg AF, Zand MS, Keefer MC, Martinez-Sobrido L, Kobie JJ. 2018. A Highly Potent and Broadly Neutralizing H1 Influenza-Specific Human Monoclonal Antibody. Sci Rep 8:4374.

36. Basu M, Piepenbrink MS, Francois C, Roche F, Zheng B, Spencer DA, Hessell AJ, Fucile CF, Rosenberg AF, Bunce CA, Liesveld J, Keefer MC, Kobie JJ. 2020. Persistence of HIV-1 Env-Specific Plasmablast Lineages in Plasma Cells after Vaccination in Humans. Cell Rep Med 1.

37. Robbie GJ, Criste R, Dall'acqua WF, Jensen K, Patel NK, Losonsky GA, Griffin MP. 2013. A novel investigational Fc-modified humanized monoclonal antibody, 
motavizumab-YTE, has an extended half-life in healthy adults. Antimicrob Agents Chemother 57:6147-53.

38. Ye C, Chiem K, Park JG, Silvas JA, Morales Vasquez D, Sourimant J, Lin MJ, Greninger AL, Plemper RK, Torrelles JB, Kobie JJ, Walter MR, de la Torre JC, Martinez-Sobrido L. 2021. Analysis of SARS-CoV-2 infection dynamic in vivo using reporter-expressing viruses. Proc Natl Acad Sci U S A 118.

39. Park JG, Oladunni FS, Chiem K, Ye C, Pipenbrink M, Moran T, Walter MR, Kobie J, Martinez-Sobrido L. 2021. Rapid in vitro assays for screening neutralizing antibodies and antivirals against SARS-CoV-2. J Virol Methods 287:113995.

40. Ackerman ME, Moldt B, Wyatt RT, Dugast AS, McAndrew E, Tsoukas S, Jost S, Berger CT, Sciaranghella G, Liu Q, Irvine DJ, Burton DR, Alter G. 2011. A robust, high-throughput assay to determine the phagocytic activity of clinical antibody samples. J Immunol Methods 366:8-19. 
A $\mathbf{N}$

SARS-CoV S1

B
C

c S2-STBL c s1/s2 Chimera
SARS-CoV-2 S2

SARS-CoV-2 S2
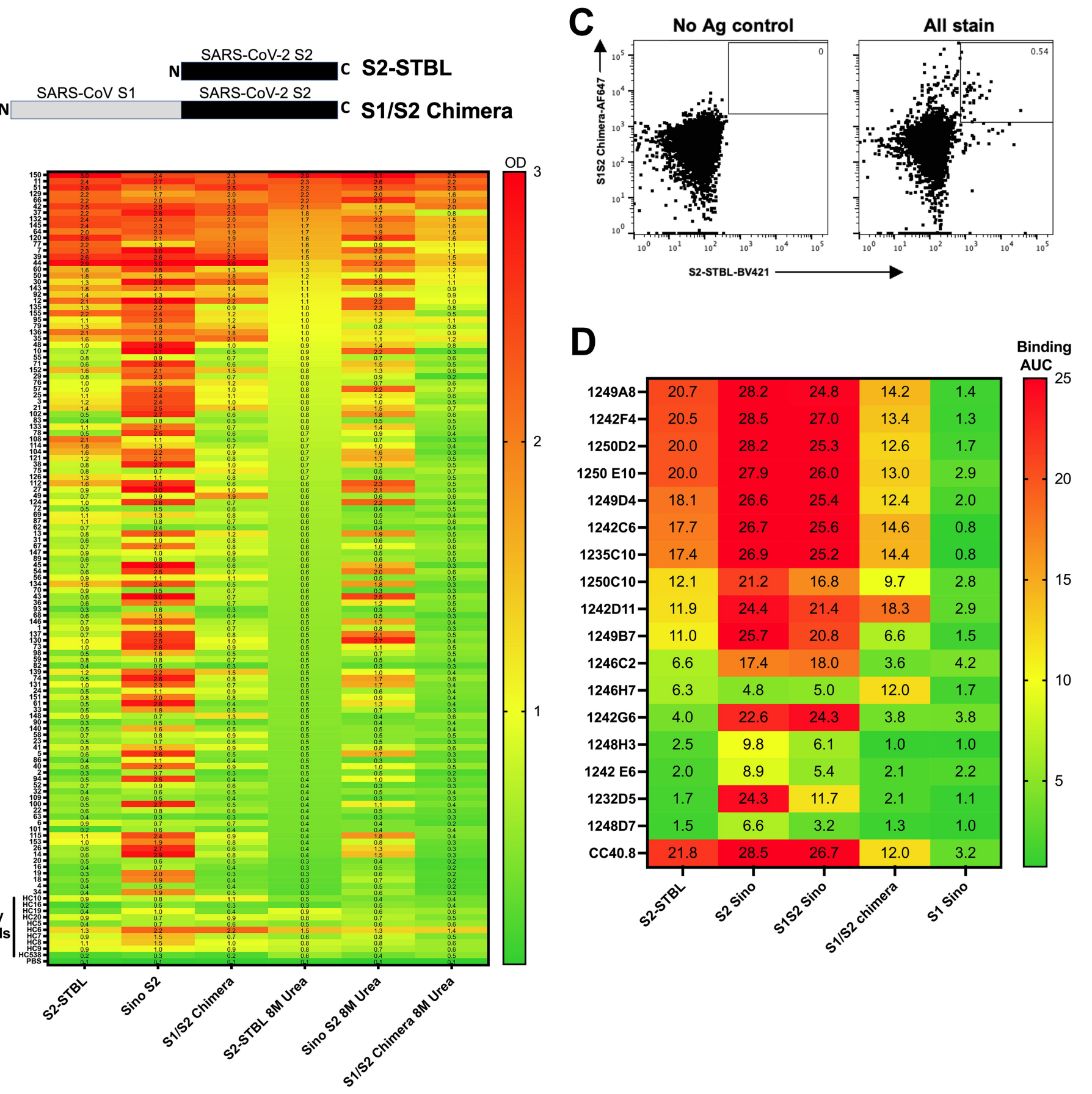

Healthy Controls 
A

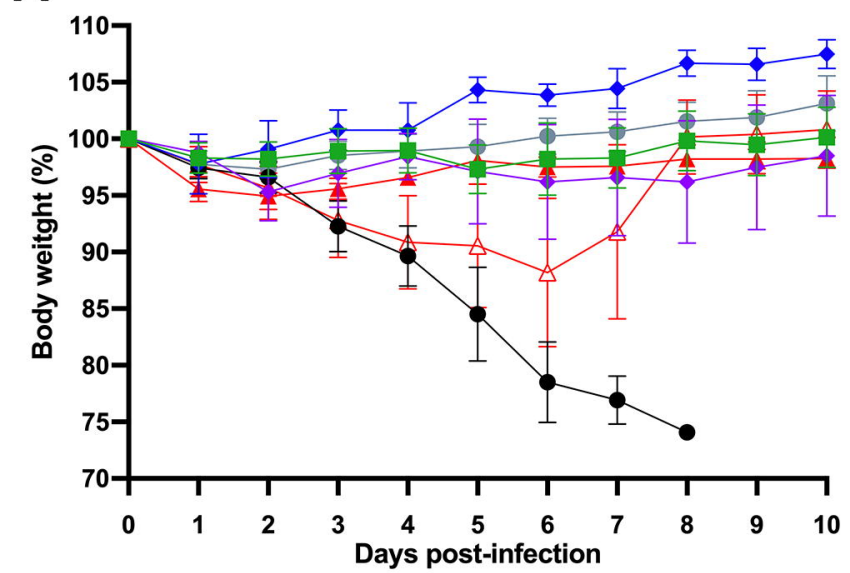

- Isotype Control $\triangle 10 \mathrm{mg} / \mathrm{kg} 1249 \mathrm{~A} 8$

- Mock-infected $\quad 40 \mathrm{mg} / \mathrm{kg} 1249 \mathrm{~A} 8$

C
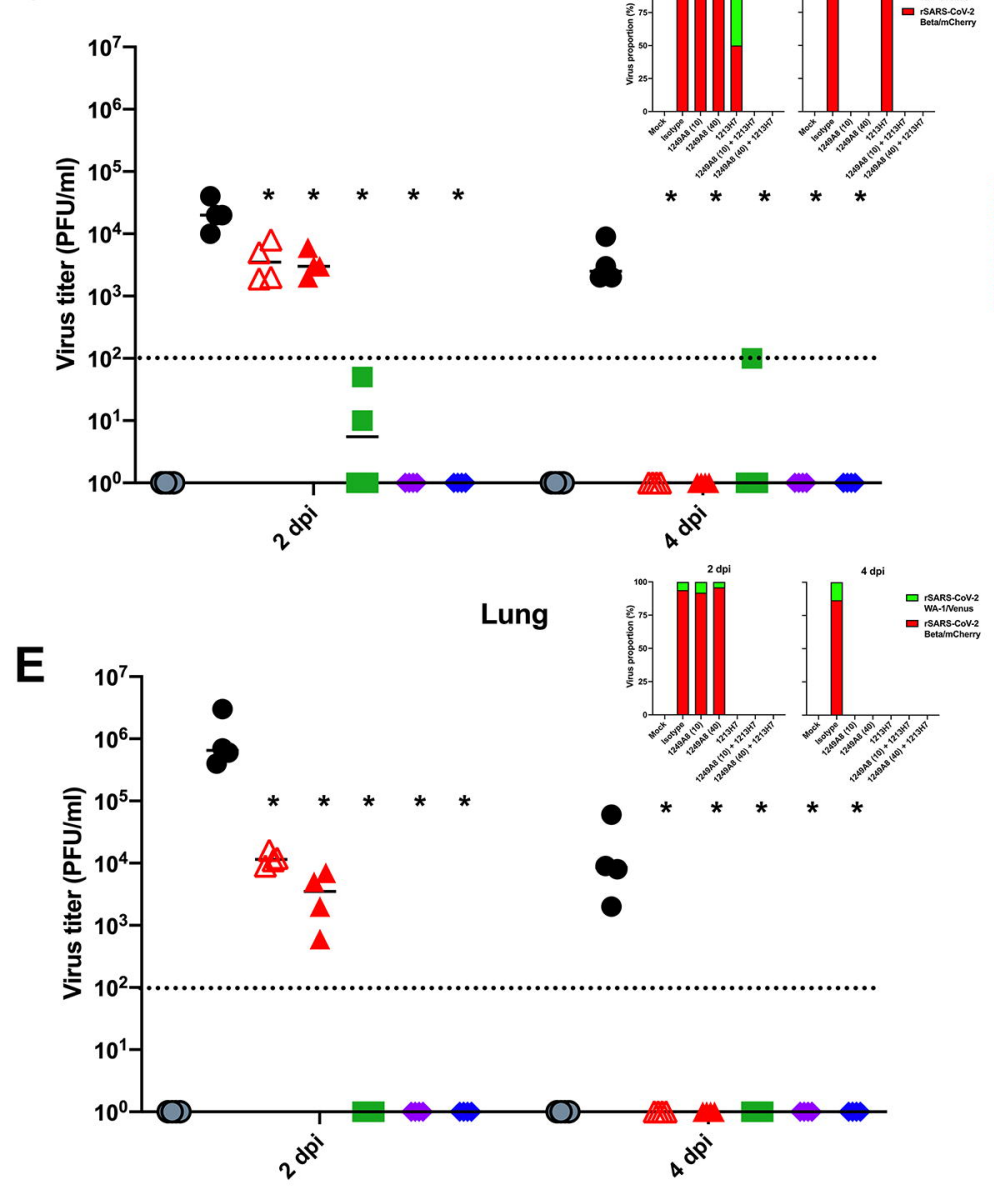

G

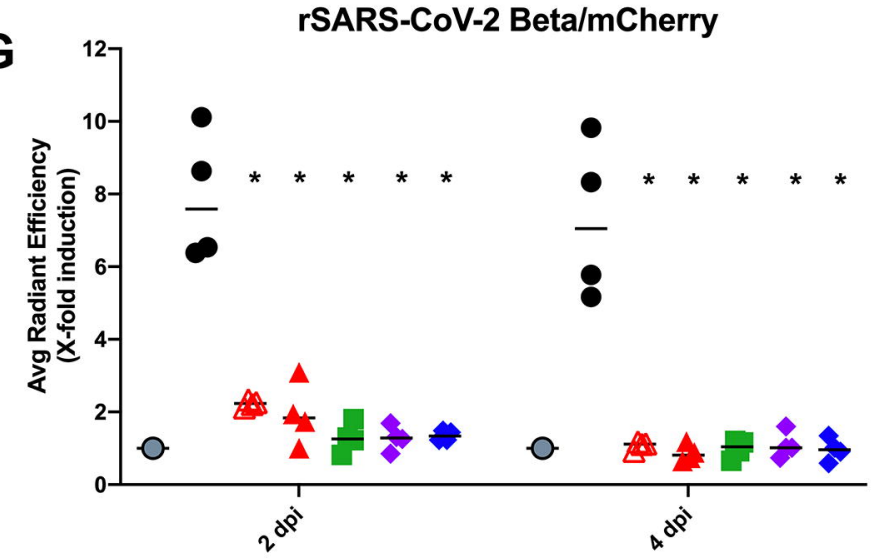

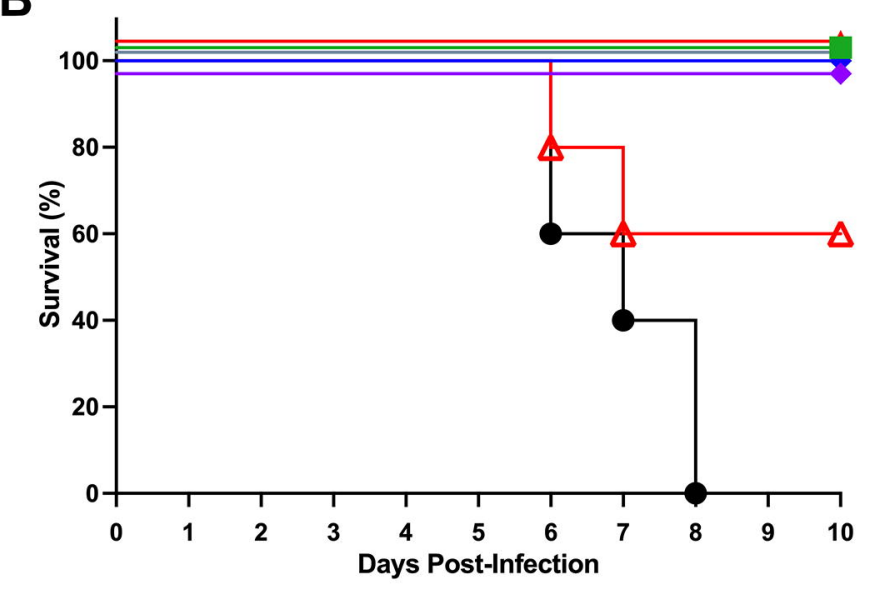

$1213 \mathrm{H} 7$

D

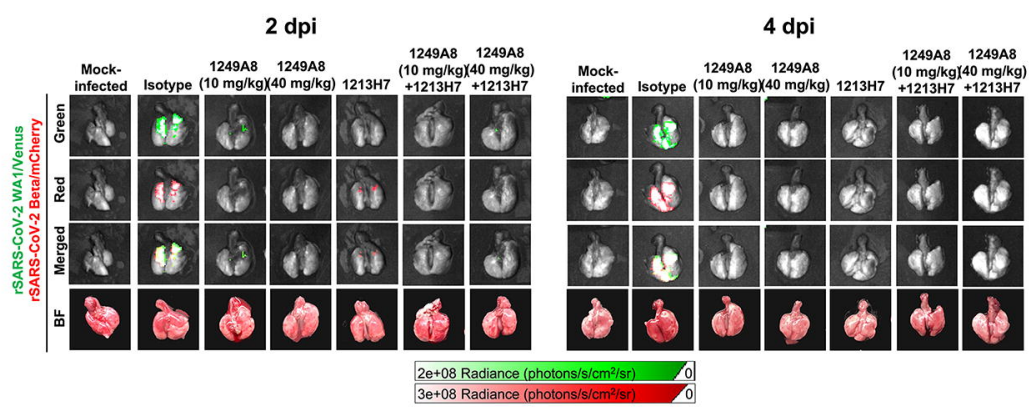

F

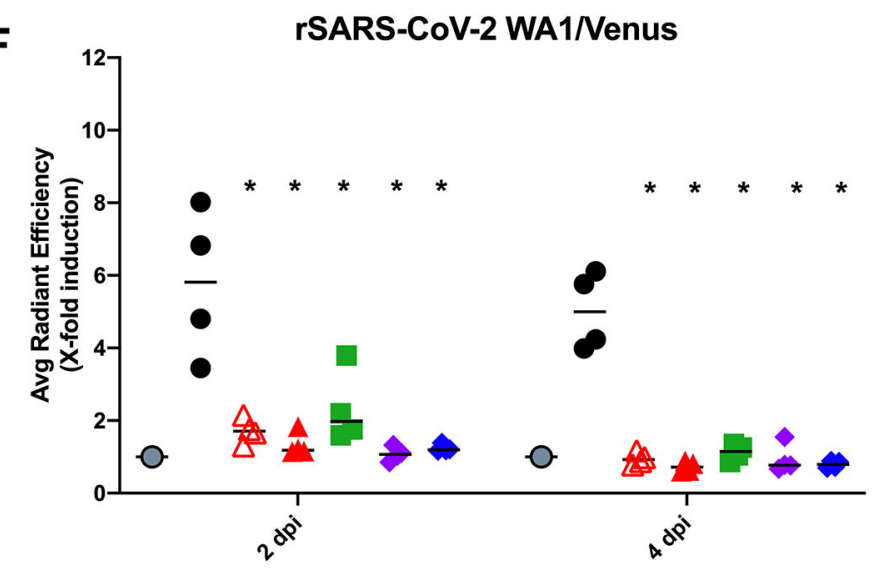

H

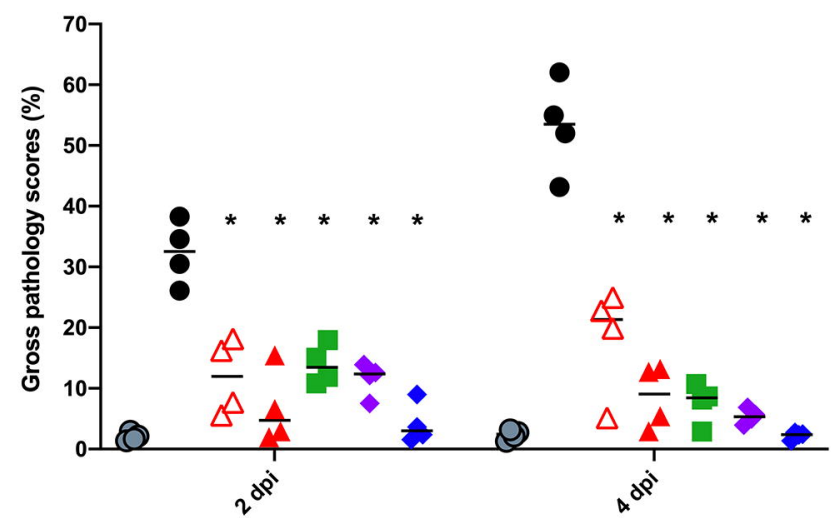



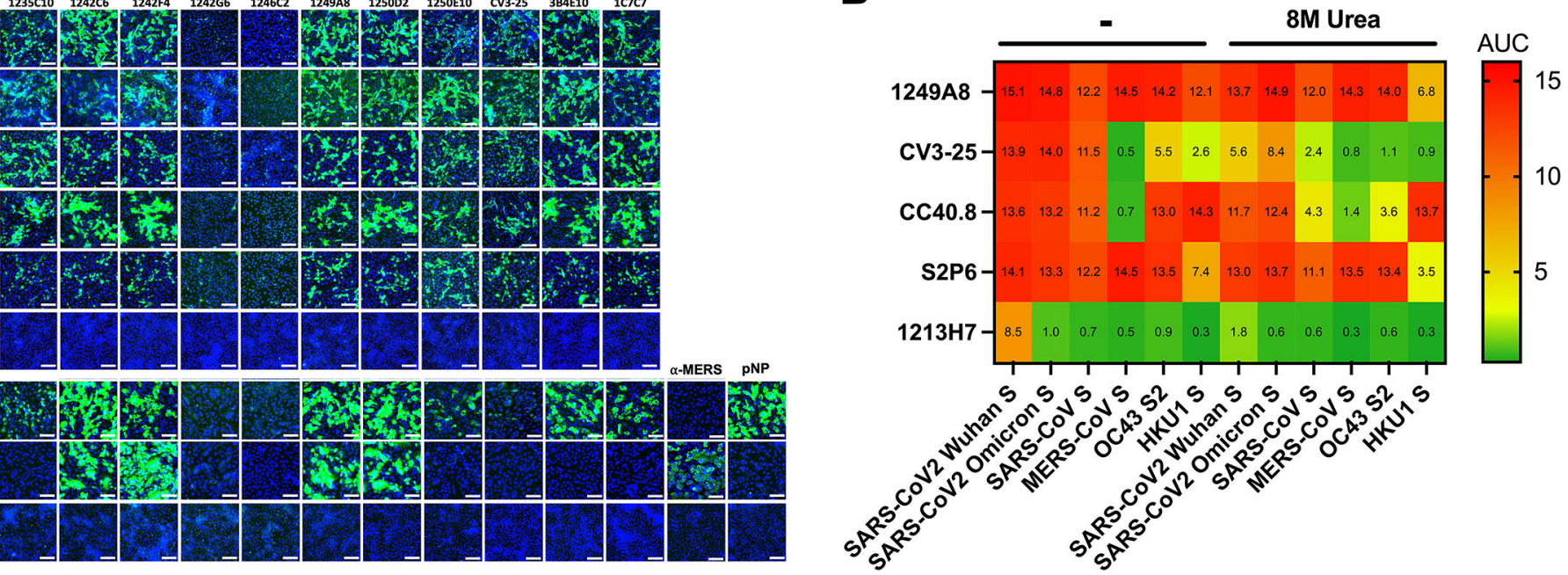

C

\begin{tabular}{|l|}
\hline \\
\hline hmAb \\
\hline 1249A8 \\
\hline S2P6 \\
\hline CC40.8 \\
\hline CV3-25 \\
\hline
\end{tabular}

\begin{tabular}{|c|c|c|c|}
\hline \multicolumn{4}{|c|}{ SARS-COV-2 } \\
\hline & SPR & & BLI \\
\hline ka & $\mathrm{kd}$ & $\mathrm{KD}(\mathrm{nM})$ & $\mathrm{KD}(\mathrm{nM})$ \\
\hline $2.8 \times 10^{5}$ & $5.2 \times 10^{-4}$ & 1.8 & 2.85 \\
\hline $3.4 \times 10^{5}$ & $3.3 \times 10^{-3}$ & 9.7 & \\
\hline $2.4 \times 10^{5}$ & $3.8 \times 10^{-4}$ & 1.6 & \\
\hline $2.4 \times 10^{5}$ & $6.1 \times 10^{-4}$ & 2.5 & \\
\hline
\end{tabular}

SARS-CoV

MERS-CoV
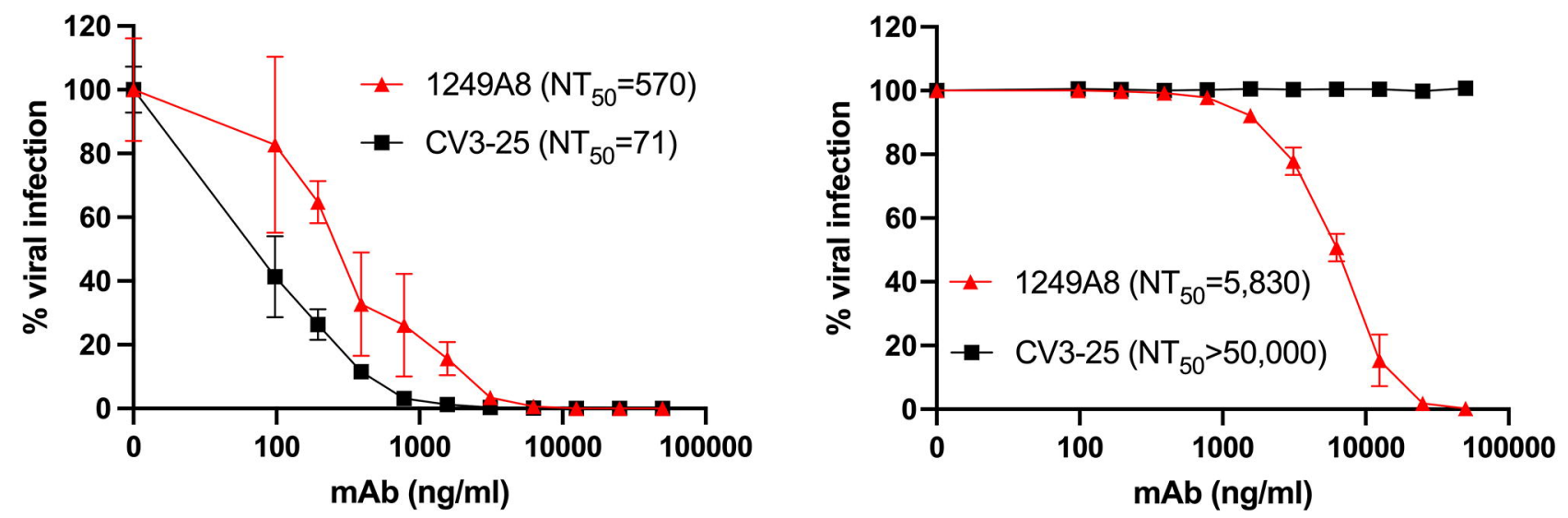

E

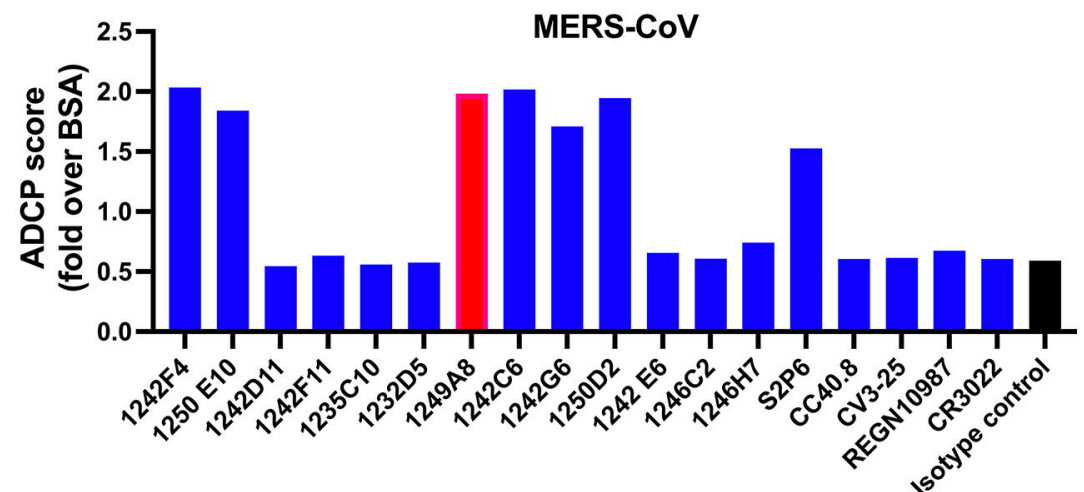


Omicron

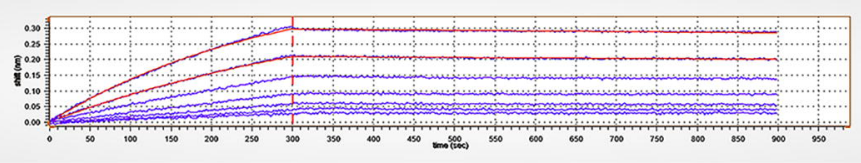

SARS-CoV-2 Omicron

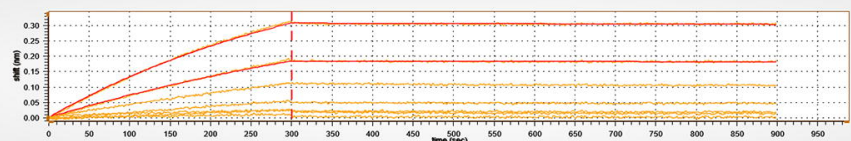

\begin{tabular}{|l|c|c|c|}
\hline Spike Protein & $\mathrm{ka}\left(\mathrm{M}^{-1} \mathrm{sec}^{-1}\right)$ & $\mathrm{Kd}\left(\mathrm{sec}^{-1}\right)$ & $\mathrm{KD}(\mathrm{nM})$ \\
\hline Wuhan & $5.88 \times 10^{4}$ & $7.18 \times 10^{-5}$ & 1.22 \\
\hline Omicron & $4.63 \times 10^{4}$ & $2.40 \times 10^{-5}$ & 0.517 \\
\hline
\end{tabular}

C Nasal turbinate

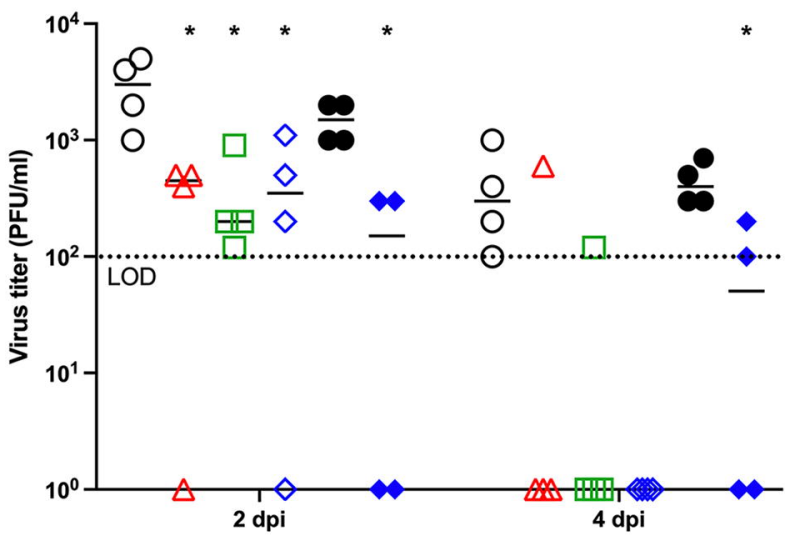

Isotype IP $\triangle 1249$ A8 IP

Mock-infected Isotype IN

D

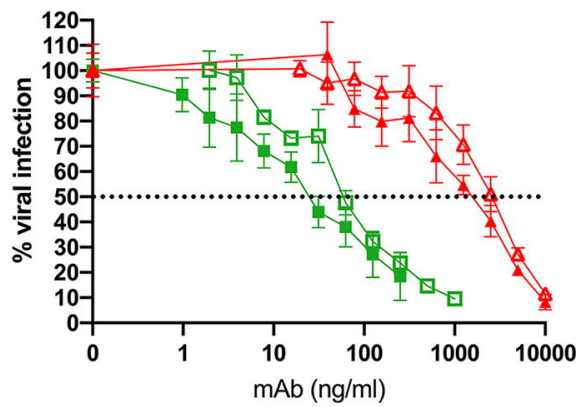

$\square 1213 \mathrm{H} 7\left(\mathrm{NT}_{50}=63.7\right) \quad \triangle 1249 \mathrm{~A} 8\left(\mathrm{NT}_{50}=2407\right)$

$-1213 \mathrm{H} 7+1249 \mathrm{~A} 8(\mathrm{C})\left(\mathrm{NT}_{50}=25.8\right) \rightarrow 1249 \mathrm{~A} 8+1213 \mathrm{H} 7(\mathrm{C})\left(\mathrm{NT}_{50}=1338\right)$

Lung

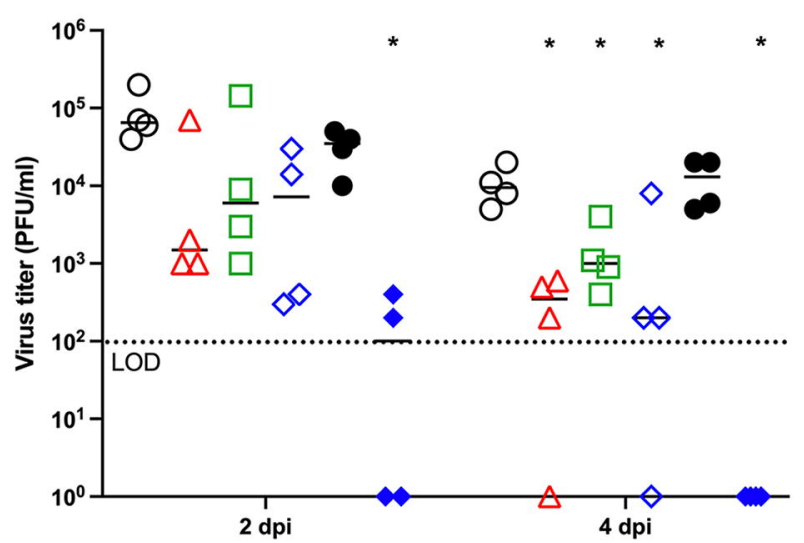

E

Lung pathology

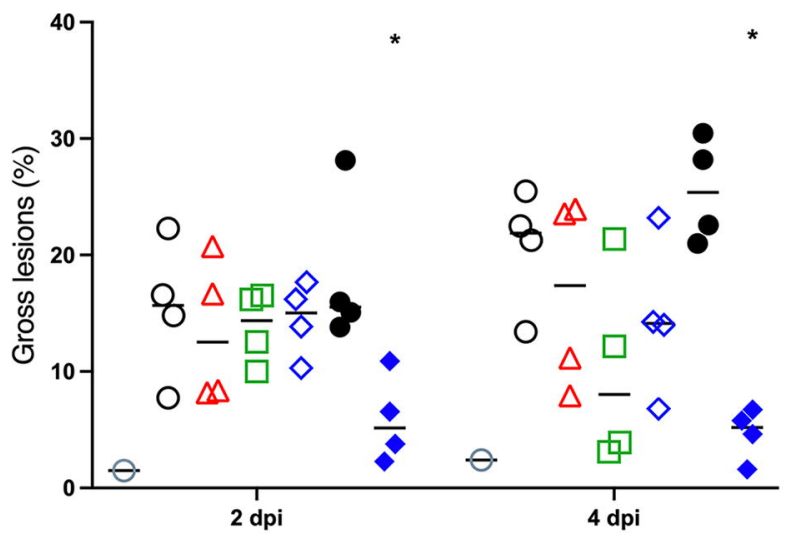


A SARS-CoV-2 Delta

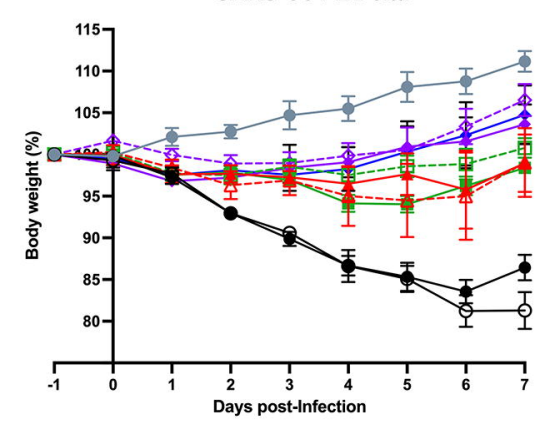

B

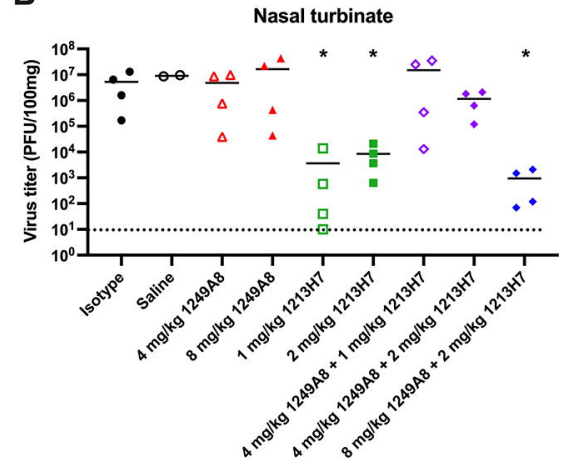

Mock-infected

- Isotype

Q Saline

\. $4 \mathrm{mg} / \mathrm{kg}$ 1249A8

- $8 \mathrm{mg} / \mathrm{kg} 1249 \mathrm{~A} 8$

ㅂ. $1 \mathrm{mg} / \mathrm{kg} 1213 \mathrm{H} 7$

-를 $2 \mathrm{mg} / \mathrm{kg} 1213 \mathrm{H} 7$

$\diamond .4 \mathrm{mg} / \mathrm{kg} 1249 \mathrm{~A} 8+1 \mathrm{mg} / \mathrm{kg} 1213 \mathrm{H} 7$

$\rightarrow 4 \mathrm{mg} / \mathrm{kg} 1249 \mathrm{~A} 8+2 \mathrm{mg} / \mathrm{kg} 1213 \mathrm{H} 7$

- $8 \mathrm{mg} / \mathrm{kg} 1249 \mathrm{~A} 8+2 \mathrm{mg} / \mathrm{kg} 1213 \mathrm{H} 7$
C

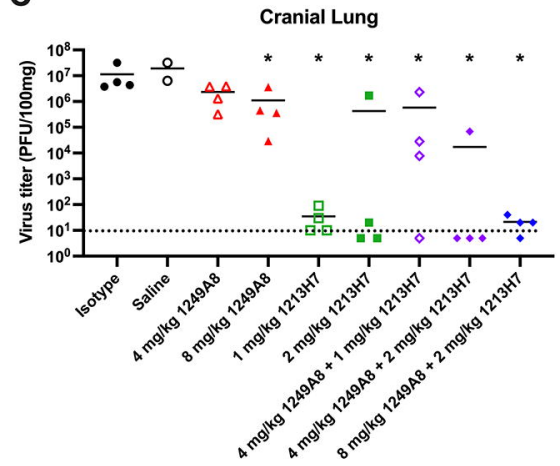

D

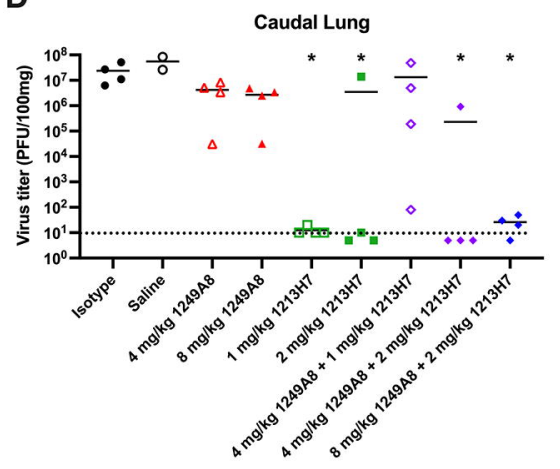


A

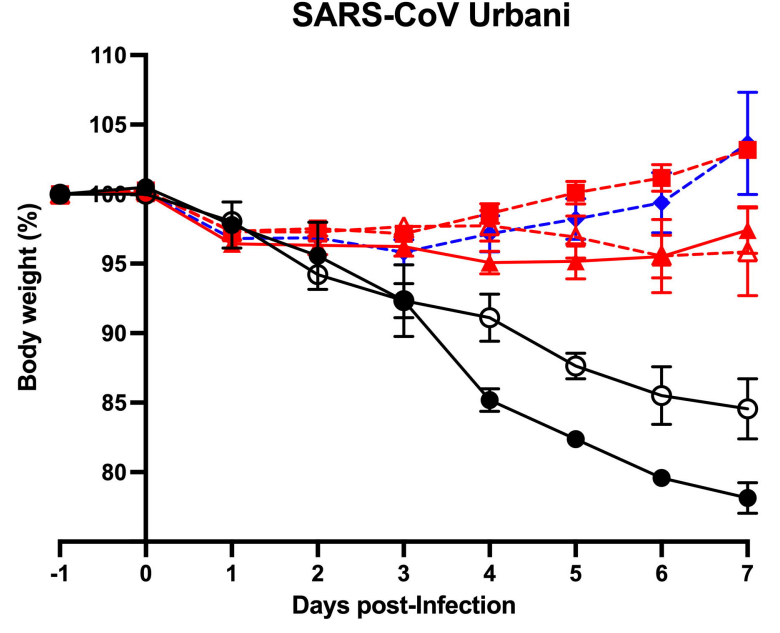

Isotype

$\vartheta$ Saline

A. $2 \mathrm{mg} / \mathrm{kg} 1249 \mathrm{~A} 8$

- $4 \mathrm{mg} / \mathrm{kg} 1249 \mathrm{~A} 8$

-7 $8 \mathrm{mg} / \mathrm{kg} 1249 \mathrm{~A} 8$

- $8 \mathrm{mg} / \mathrm{kg} 1249 \mathrm{~A} 8+2 \mathrm{mg} / \mathrm{kg} 1213 \mathrm{H} 7$

B

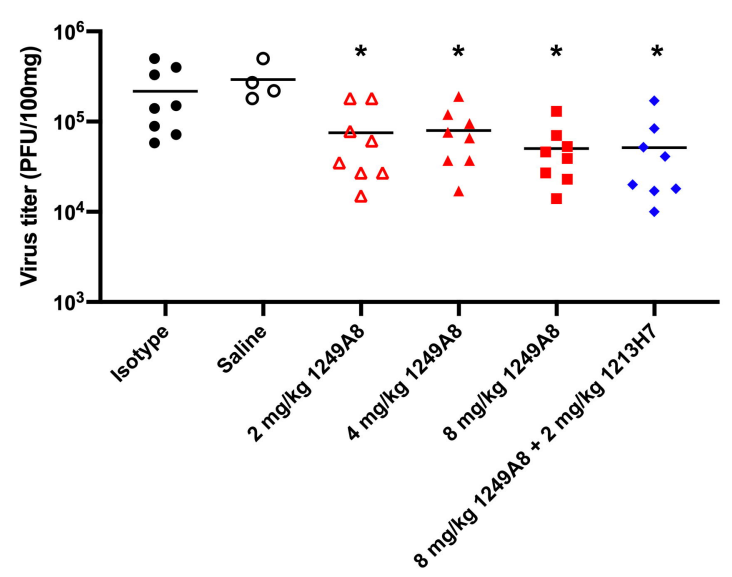

E

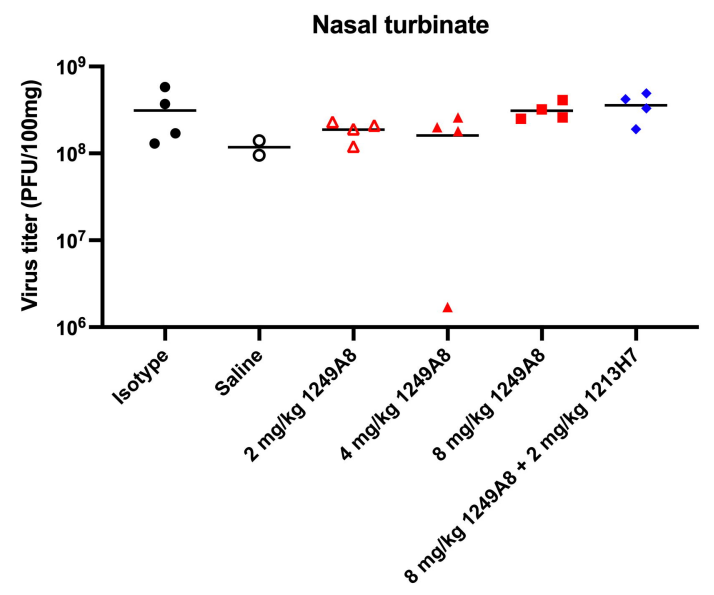

D

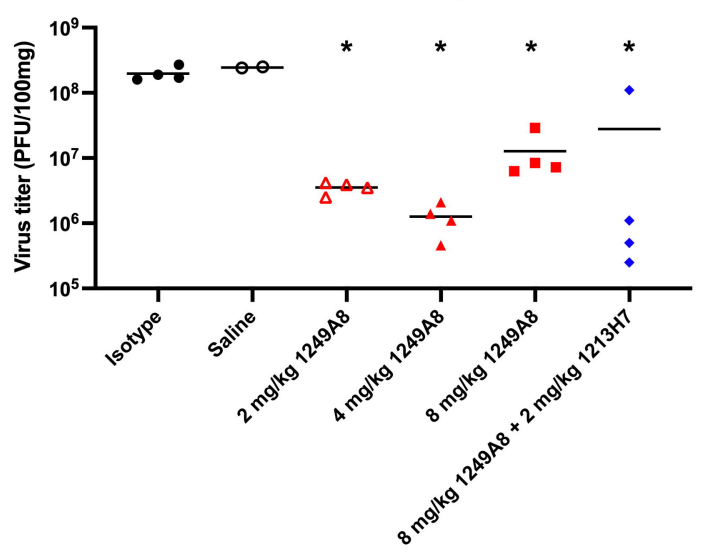

Caudal Lung

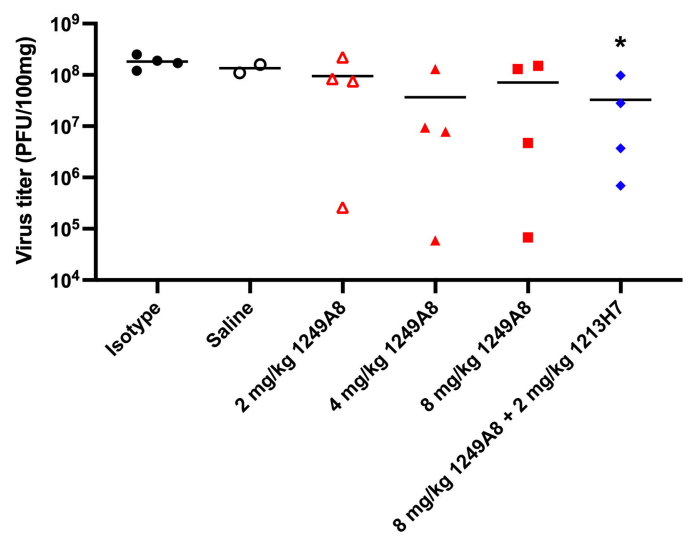


Table1. Molecular characteristics of S2 specific hmAbs.

\begin{tabular}{|c|c|c|c|c|c|c|c|c|}
\hline hMAb & Native isotype & VH & DH & JH & $\begin{array}{c}\text { Mutation } \\
\text { (\% NT/\% AA) }\end{array}$ & VL & JL & $\begin{array}{c}\text { Mutation } \\
\text { (\% NT/\% AA) }\end{array}$ \\
\hline 1249A8 & $\operatorname{lgG1}$ & VH1-46 & DH1-26 & $\mathrm{JH} 4$ & $9.7 / 16.7$ & VK3-20 & JK2 & $7.6 / 13.5$ \\
\hline $1242 C 6$ & $\operatorname{lgG1}$ & VH1-46 & DH1-26 & $\mathrm{JH} 4$ & $9.7 / 16.7$ & VK3-20 & JK2 & $6.2 / 12.5$ \\
\hline 1250D2 & $\lg G 1$ & VH1-46 & DH1-26 & $\mathrm{JH} 4$ & $9.0 / 16.7$ & VK3-20 & JK2 & $5.5 / 10.4$ \\
\hline $1242 \mathrm{~F} 4$ & $\lg G 1$ & VH1-46 & DH3-16 & $\mathrm{JH} 4$ & $12.4 / 18.8$ & VK3-20 & JK2 & $6.2 / 10.4$ \\
\hline 1249D4 & $\lg G 1$ & VH1-46 & DH1-26 & $\mathrm{JH} 4$ & $7.6 / 15.6$ & VK3-20 & JK2 & $6.9 / 12.5$ \\
\hline 1249B7 & $\operatorname{lgG1}$ & VH1-46 & DH1-26 & $\mathrm{JH} 4$ & $9.0 / 17.7$ & VK3-20 & JK2 & $6.6 / 13.5$ \\
\hline $1250 \mathrm{E} 10$ & $\operatorname{lgG1}$ & VH1-46 & $\mathrm{DH} 1-26$ & JH5 & $13.4 / 20.8$ & VK3-20 & JK2 & $9.7 / 16.7$ \\
\hline 1242D11 & IgA1 & VH3-7 & DH3-22 & $\mathrm{JH} 2$ & $2.0 / 4.1$ & VK3-20 & JK2 & $2.1 / 4.2$ \\
\hline $1242 \mathrm{E} 6$ & $\operatorname{lgG1}$ & VH3-7 & DH3-9 & JH5 & $1.0 / 1.0$ & VL2-14 & JL1 & $4.0 / 6.1$ \\
\hline $1246 C 2$ & $\operatorname{lgG3}$ & VH3-21 & DH1-26 & $\mathrm{JH} 2$ & $7.4 / 14.3$ & VK3-11 & JK4 & $6.3 / 9.5$ \\
\hline 1232D5 & $\operatorname{lgG1}$ & VH3-30 & DH6-19 & $\mathrm{JH} 4$ & $2.7 / 5.2$ & VL1-44 & JL3 & $2.4 / 4.1$ \\
\hline $1242 \mathrm{G} 6$ & $\operatorname{lgG1}$ & VH3-30 & DH3-10 & $\mathrm{JH} 4$ & $10.1 / 19.4$ & VK1-9 & JK5 & $5.3 / 10.5$ \\
\hline $1235 C 10$ & $\operatorname{lgG1}$ & VH3-49 & DH3-10 & $\mathrm{JH} 4$ & $2.0 / 3.0$ & VK4-1 & JK1 & $2.0 / 5.0$ \\
\hline $1246 \mathrm{H} 7$ & IgM & VH4-39 & DH3-16 & $\mathrm{JH} 4$ & $4.1 / 6.1$ & VL2-11 & JL3 & $3.4 / 4.1$ \\
\hline
\end{tabular}

